Article

\title{
The Recognition of Calmodulin to the Target Sequence of Calcineurin-A Novel Binding Mode
}

\author{
Chia-Lin Chyan *, Deli Irene and Sin-Mao Lin \\ Department of Chemistry, National Dong Hwa University, Hualien 974, Taiwan; deli24@gate.sinica.edu.tw (D.I.); \\ 610312003@gms.ndhu.edu.tw (S.-M.L.) \\ * Correspondence:chyan@gms.ndhu.edu.tw; Tel.: +886-3863-3589
}

Received: 15 August 2017; Accepted: 18 September 2017; Published: 21 September 2017

\begin{abstract}
Calcineurin $(\mathrm{CaN})$ is a $\mathrm{Ca}^{2+} /$ calmodulin-dependent Ser/Thr protein phosphatase, which plays essential roles in many cellular and developmental processes. CaN comprises two subunits, a catalytic subunit (CaN-A, $60 \mathrm{kDa}$ ) and a regulatory subunit (CaN-B, $19 \mathrm{kDa})$. CaN-A tightly binds to CaN-B in the presence of minimal levels of $\mathrm{Ca}^{2+}$, but the enzyme is inactive until activated by CaM. Upon binding to $\mathrm{CaM}, \mathrm{CaN}$ then undergoes a conformational rearrangement, the auto inhibitory domain is displaced and thus allows for full activity. In order to elucidate the regulatory role of $\mathrm{CaM}$ in the activation processes of $\mathrm{CaN}$, we used NMR spectroscopy to determine the structure of the complex of $\mathrm{CaM}$ and the target peptide of $\mathrm{CaN}(\mathrm{CaNp})$. The CaM/CaNp complex shows a compact ellipsoidal shape with $8 \alpha$-helices of CaM wrapping around the CaNp helix. The RMSD of backbone and heavy atoms of twenty lowest energy structures of CaM/CaNp complex are 0.66 and $1.14 \AA$, respectively. The structure of CaM/CaNp complex can be classified as a novel binding mode family 1-18 with major anchor residues Ile ${ }^{396}$ and $\mathrm{Leu}^{413}$ to allocate the largest space between two domains of CaM. The relative orientation of CaNp to CaM is similar to the CaMKK peptide in the 1-16 binding mode with $\mathrm{N}$ - and C-terminal hydrophobic anchors of target sequence engulfed in the hydrophobic pockets of the $\mathrm{N}$ - and C-domain of CaM, respectively. In the light of the structural model of $\mathrm{CaM} / \mathrm{CaNp}$ complex reported here, we provide new insight in the activation processes of $\mathrm{CaN}$ by $\mathrm{CaM}$. We propose that the hydrophobic interactions between the $\mathrm{Ca}^{2+}$-saturated C-domain and C-terminal half of the target sequence provide driving forces for the initial recognition. Subsequent folding in the target sequence and structural readjustments in CaM enhance the formation of the complex and affinity to calcium. The electrostatic repulsion between $\mathrm{CaM} / \mathrm{CaNp}$ complex and AID may result in the displacement of AID from active site for full activity.
\end{abstract}

Keywords: calmodulin; calcineurin; NMR; protein structure

\section{Introduction}

Calmodulin $(\mathrm{CaM})$ is a highly conserved $17 \mathrm{kDa}$ eukaryotic $\mathrm{Ca}^{2+}$-binding protein. In response to a $\mathrm{Ca}^{2+}$ signal, $\mathrm{CaM}$ interacts with and regulates various proteins including calmodulin-dependent protein kinases and phosphatases, cytoskeletal proteins, ion channels, and pumps. Unraveling its diverse roles in activation mechanisms and target recognition has received extensive attention [1-7]. CaM contains two globular domains connected by a flexible linker [8,9]. Each domain contains two EF-hand $\mathrm{Ca}^{2+}$-binding motifs. Although the two domains share high degree of homology in sequence, they exhibit subtle differences in structures and $\mathrm{Ca}^{2+}$ affinity [10-12]. $\mathrm{Ca}^{2+}$ influx triggers conformational changes of CaM resulting in the opening of the hydrophobic pockets allowing the association with various target proteins. Therefore, the interplay of $\mathrm{Ca}^{2+}$-concentration and affinity between CaM and target proteins controls and tunes CaM's diverse recognition network. Since high resolution structures of the CaM in complex with its target enzymes are mostly unavailable to date, 
the three-dimensional structures of the complex of CaM and various CaM-binding domains of its target enzymes have been used as mimetic structure models in the past [13-41]. It has been shown that CaM adopted virtually identical backbone structures upon association with either CaM-dependent enzyme or its CaM-binding domain, as judged by backbone chemical shift changes in solution [42]. Hence the CaM-binding domains in the form of peptides may serve as structure surrogates in the study of the CaM-target protein interactions. Although little sequence homology has been found in the canonical target sequences, the positions of several bulky hydrophobic residues are often conserved, allowing further classification of target sequences into recognition motifs. Among the solved structures in the 1:1 stoichiometry class, several CaM binding modes have been classified by the spacing between conserved hydrophobic anchor residues in the target peptide, which forms an $\alpha$-helical structure. The widely adopted structural model is that the $\alpha$-helical target peptide lies in a hydrophobic channel formed by the two domains of CaM. The predominant interactions included mostly hydrophobic forces between the anchor residues of the target peptide and two hydrophobic pockets provided by CaM. The 1-14 CaM-target binding mode, the prototype for CaM-target interactions in the 1:1 stoichiometry, was first defined in the structures of CaM bound to the M13 peptide derived from the skeletal muscle myosin light chain kinase. The hydrophobic anchor, Trp 1 and Phe 14 of M13 was engulfed in the hydrophobic pocket of the C- and N-terminal domain of CaM, respectively [13,14]. Subsequently, the 1-7, 1-10,1-16, and 1-18 binding types were found in NMDA receptor NR1 subunit [28], CaMKII [15,16], CaMKK [17,19], and $\mathrm{Ca}^{2+}$ pump [32]. In most of the solved structures, the relative orientation of the target peptide to CaM are similar to the CaM/M13 peptide complex, with $\mathrm{N}$ - and C-terminal hydrophobic anchors of target sequence engulfed in the hydrophobic pockets of the C-and N-domain of CaM, respectively. However, the orientation of the $\alpha$-helix of CaMKK is opposite to that of the other target sequences with respect to the two domains of CaM. In addition to the 1:1 binding class, two more classes of CaM/CaM-binding domain complex have been identified by the 1:2, and 2:2 (CaM:CaM-binding peptide) stoichiometric ratios [2,3,20,22,43,44]. The case of $\mathrm{CaM}$, a central coordinator for many target proteins clearly indicates that the conformation of CaM depends on its interacting partners and environment. It is of great interest to determine the crucial residues in these target sequences that are responsible for driving the interaction with CaM, as the information may assist in mapping the entire network of CaM-mediated pathways. Hence, together with the proteomic and structural genomic analyses on protein interactions, the entire complement of protein structure-function relationships will take shape.

Calcineurin $(\mathrm{CaN})$ is a unique $\mathrm{Ca}^{2+} /$ calmodulin-dependent Ser/Thr protein phosphatase. CaN directs the flow of information of calcium signals to downstream effectors that controls cellular responses and gene expressions [45-50]. CaN comprise two subunits, a catalytic subunit (CaN-A, $60 \mathrm{kDa}$ ) and a regulatory subunit $(\mathrm{CaN}-\mathrm{B}, 19 \mathrm{kDa})$. The sequences are highly conserved among different organisms, although there are three isoforms of $\mathrm{CaN}-\mathrm{A}$, and two isoforms of CaN-B in human. CaN-A $\alpha$-isoform is composed of the catalytic domain (residue 1-348) and the regulatory domain (residue 349-521) comprising of the CaN-B binding domain (BBD; residue 348-369), CaM target domain (residue 391-414) and auto-inhibitory domain (AID; residue 468-491) [51,52]. CaN-A tightly binds to CaN-B in the presence of minimal level of $\mathrm{Ca}^{2+}$, but the enzyme is inactive until activated by CaM. The activation of $\mathrm{CaN}$ by $\mathrm{CaM}$ including several sequential steps was proposed more than two decades ago $[53,54]$. The conformational change of $\mathrm{CaN}$ is triggered by occupancy of calcium ions to the low affinity sites of CaN-B subunit which causes the dissociation of the CaM target domain from the CaN-B binding domain. Subsequently, CaM recognizes this target region and leads to the displacement of AID from the active site and full activation. Although this activation model is in accord with most biochemical results, there is still limited structural information. The crystallographic structure of $\mathrm{CaN}$ shows that the AID adopts a helical conformation and blocks the active site of CaN (PDB 1AUI), whereas the regulatory domain of CaN-A is invisible in the electron density map except AID and BBD [55]. Although many research groups, including us, have aimed to put back the missing pieces for the activation action of $\mathrm{CaM}$ on $\mathrm{CaN}$ [56-58], there is no high resolution structure solved 
for the entire $\mathrm{CaN}$ and CaM complex till now. Instead, two groups solved the crystal structures of $\mathrm{CaM}$ and the target peptide of $\mathrm{CaN}$ for structural surrogates $[59,60]$. The crystallographic structures (2R28 and 2W73) show 2:2 domain swapping structures, in which the N-domain of one CaM molecule and C-domain of a second CaM molecule interact with a target peptide of CaN, the rest C- and $\mathrm{N}$-domain of the two CaM molecules interact with a second target peptide of CaN. While majority of the evidences by us and other groups support the 1:1 wrapped around structure under physiological conditions [61-63], no solution structure of CaM and the target peptide of CaN has been obtained. A crystallographic structure of CaM with the target peptide of $\mathrm{CaN}$ in 1:1 stoichiometric ratio was recently solved in $1.9 \AA$ resolution [41]. Our solution phase structure further verifies their conclusion arrived at by x-ray crystallography, a methodology that sometimes produces structural artefact due to crystal lattice packing. Here, we report the solution structure of $\mathrm{CaM}$ and the target sequence of $\mathrm{CaN}$ (residue 391-414 in CaN-A; CaNp) by NMR. In light of the complex structure reported here, we also proposed new insight in the recognition and activation processes of $\mathrm{CaN}$ by CaM. We suggested that the interplay of hydrophobic and ionic interactions controls and tunes the recognition and activation processes of $\mathrm{CaN}$ by CaM.

\section{Results and Discussion}

\subsection{Stoichiometry and Secondary Structure Analysis of CaNp upon Binding to CaM by Circular Dichroism Spectroscopy}

The change in the secondary structure of CaM upon the complex formation with CaNp has been investigated by CD spectroscopy (Figure 1). The free CaM displayed a typical helical structure with minima molar CD absorption coefficient $\left(\Delta \varepsilon_{M}\right)$ at $222 \mathrm{~nm}$ and $208 \mathrm{~nm}$, whereas the CaNp alone showed mostly random-coil structure in the aqueous solution.

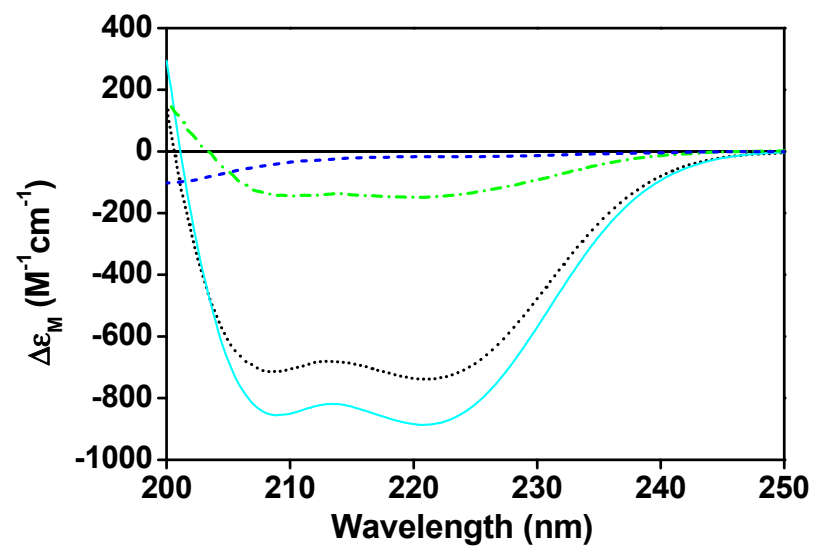

Figure 1. The secondary structure of CaM/CaNp complex. Far-UV CD spectra of CaM (black dotted line), free CaNp (blue dashed line), the complex of CaM and CaNp in a 1:1 molar ratio (cyan solid line), and the difference between the CaM/CaNp complex and free CaM (green dashed/dotted line). The CD spectra were taken at the concentration of $10 \mu \mathrm{M} \mathrm{CaM}$ and/or $10 \mu \mathrm{M} \mathrm{CaNp}$ in $100 \mathrm{mM} \mathrm{KCl}$, and $2 \mathrm{mM} \mathrm{CaCl}_{2}$ at $\mathrm{pH}$ 6.5.

When an equivalent concentration of $\mathrm{CaNp}$ was added to the CaM solution, the negative molar ellipticity at $208 \mathrm{~nm}$ and $222 \mathrm{~nm}$ increased. When more than one equivalent concentration of CaNp was added to the CaM solution, the negative molar ellipticity at $208 \mathrm{~nm}$ and $222 \mathrm{~nm}$ remained almost the same. The data suggested the complex formation with the molar ratio 1:1. In addition, the results showed an increase of $\alpha$-helical content upon complex formation. Structural information of the CaM-peptide complexes extracted from the protein data bank (PDB) indicated that CaM itself usually did not gain $\alpha$-helical structure upon peptide binding. Therefore, we assumed that the increase in $\alpha$-helical content was mostly attributed by the bound CaNp. The spectral difference between the 
CaM/CaNp complex and free CaM displayed in Figure 1 was used to estimate the $\alpha$-helical content in the CaNp when associated with CaM. An approximately $71 \% \alpha$-helical content in the bound CaNp was estimated by the Dichroweb program [64,65], corresponds to a 17-residue $\alpha$-helix in CaNp. This observation was in good agreement with many CaM-binding peptides in the 1:1 binding class.

\subsection{Hydrodynamic Properties of CaM/CaNp Complex by Dynamic Light Scattering (DLS) and NMR Spectral} Line Width

The hydrodynamic properties of CaM/CaNp complex were investigated by dynamic light scattering (DLS) and NMR spectroscopy. The inset in Figure 2A presents the time-average distribution of hydrodynamic radius $\left(\mathrm{R}_{\mathrm{H}}\right)$ of CaM/CaNp complex obtained from nine DLS measurements. The data showed that the complex formed a single species with average $\mathrm{R}_{\mathrm{H}} 2.61 \mathrm{~nm}$ in solution with no evidence of polymeric forms with larger $\mathrm{R}_{\mathrm{H}}$ values. Calibrated with molecular weight standards shown in Figure $2 \mathrm{~A}$ the $\mathrm{R}_{\mathrm{H}}$ of $\mathrm{CaM} / \mathrm{CaNp}$ complex corresponded to a globular protein of $\mathrm{M}_{\mathrm{r}} 17.2 \mathrm{kDa}$, roughly consistent with the theoretical $\mathrm{M}_{\mathrm{r}}$ calculated from the sequence of CaM and CaNp in a 1:1 ratio $(19.5 \mathrm{kDa})$.

In addition to the DLS technique, linewidths in the NMR spectrum are also frequently used to probe the effective hydrodynamic properties of biomolecules. The larger molecular size causes an increase in the effective hydrodynamic volume, leading to a larger rotational correlation time $\left(\tau_{c}\right)$ and a corresponding increase in the NMR spectral linewidth. As shown in Figure 2B, the NMR resonances of $\mathrm{CaM}$ when associated with $\mathrm{CaNp}$ were sufficiently sharp compared to those in free CaM, the half-width of NH resonance of G61, G134, I100 I27, N137 of bound CaM was similar to or even smaller than the half-width of resonance in free CaM respectively. Similar phenomenon were found in $2 \mathrm{D}^{1} \mathrm{H}-{ }^{15} \mathrm{~N}$ HSQC spectra, the average half-width of 39 isolated $\mathrm{NH}$ resonances of bound CaM was similar to the average half-width of resonances in free CaM (Table S2). Our data from the DLS and NMR line width experiments indicated that CaM/CaNp complex existed in a 1:1 ratio form in solution. The domain-swapping dimeric CaM/CaNp complex found in the crystal structures (PDB 2R28 and 2W73) with 2:2 ratio was not observed in solution.

\subsection{Activity of $\mathrm{CaN}$ is Activated by CaM}

In order to understand the mechanism of CaM to activate CaN phosphatase, the phosphatase activities of CaN were assayed fluorometrically. As shown in Figure 3, when assayed without CaM, $\mathrm{CaN}$ was much less active with average activity $0.12 \mu \mathrm{M} / \mathrm{h}$ product produced per $\mu \mathrm{g}$ CaN used. The low residual activity of $\mathrm{CaN}$ was probably due to the existence of minor proteolytic form of $\mathrm{CaN}$ A subunit which lacks the regulatory domain.

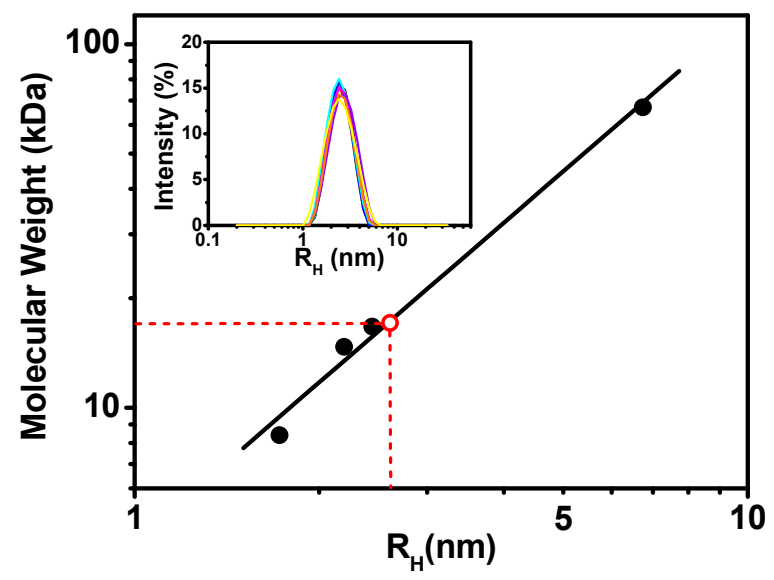

(A)

Figure 2. Cont. 


\section{free CaM}
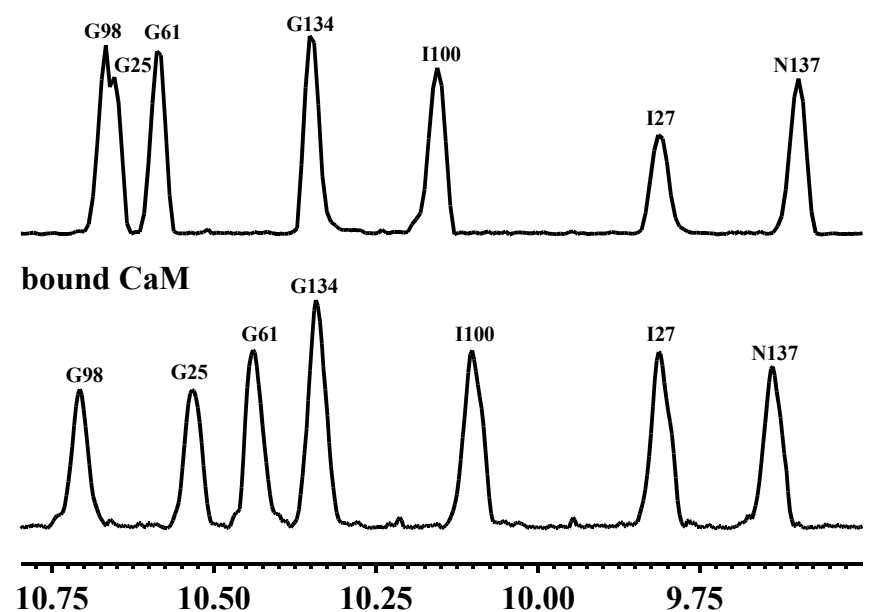

(B)

Figure 2. Stoichiometric ratio measurements of CaM/CaNp complex by DLS and NMR. (A) Dynamic Light Scattering (DLS) measurements on standard proteins and CaM/CaNp complex. A double logarithmic calibration curve of $R_{H}$ versus $M_{r}$, shown in black line was generated using DLS measurements of standard proteins including BSA $\left(\mathrm{R}_{\mathrm{H}} 6.75 \mathrm{~nm}, \mathrm{M}_{\mathrm{r}} 67 \mathrm{kDa}\right), \mathrm{CaM}\left(\mathrm{R}_{\mathrm{H}} 2.44 \mathrm{~nm}\right.$, $\left.M_{\mathrm{r}} 16.7 \mathrm{kDa}\right)$, lysozyme $\left(\mathrm{R}_{\mathrm{H}} 2.20 \mathrm{~nm}, \mathrm{M}_{\mathrm{r}} 14.7 \mathrm{kDa}\right)$, and ubiquitin $\left(\mathrm{R}_{\mathrm{H}} 1.7 \mathrm{~nm}, \mathrm{M}_{\mathrm{r}} 8.4 \mathrm{kDa}\right)$, which were shown in black circles. Hydrodynamic radius $\left(\mathrm{R}_{\mathrm{H}}\right)$ distribution of $\mathrm{CaM} / \mathrm{CaNp}$ complex was determined by DLS. Nine DLS measurements were performed for CaM/CaNp complex, and the average $R_{H}$ for CaM/CaNp complex is $2.61 \mathrm{~nm}$ (inset). The $\mathrm{M}_{\mathrm{r}}$ of CaM/CaNp was then estimated to 17.2 kDa by linear intrapolation by red dash lines. (B) 1D NMR spectral linewidth measurements on free CaM and CaM/CaNp complex. The average half-width of NH resonance of G61, G134, I100 I27, and N137 for the bound CaM is $15.5 \mathrm{~Hz}$; the average half-width of those $\mathrm{NH}$ resonances for the free $\mathrm{CaM}$ is $16.0 \mathrm{~Hz}$.

The specific activity of $\mathrm{CaN}$ increased to $0.83 \mu \mathrm{M} / \mathrm{h}$ when equivalent concentration of CaM was added to the reaction. However, the specific activity of $\mathrm{CaN}$ was $0.24 \mu \mathrm{M} / \mathrm{h}$ when $\mathrm{CaM}$ was pretreated with equivalent concentration of CaNp. Apparently, CaM loses most of its ability to activate CaN in the presence of $\mathrm{CaNp}$. Our data indicated that both $\mathrm{CaN}$ and $\mathrm{CaNp}$ competed for the binding to CaM, however, the binding of $\mathrm{CaNp}$ is much stronger than $\mathrm{CaN}$ to $\mathrm{CaM}$.

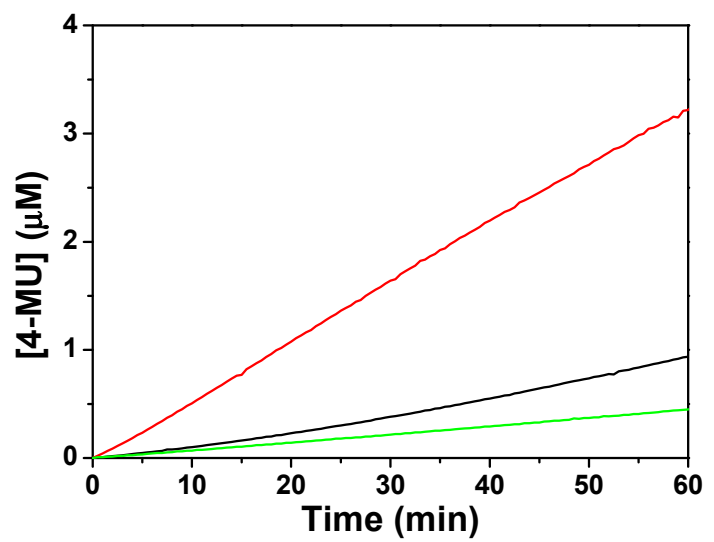

(A)

Figure 3. Cont. 


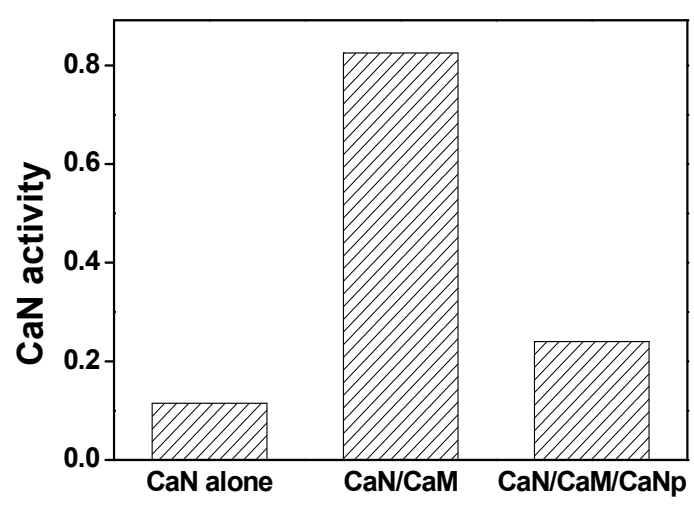

(B)

Figure 3. The phosphatase activity of CaN activated by the presence of recombinant CaM. (A) The hydrolysis of a fluorogenic substrate, 4-methylumbelliferyl-phosphate (4-MUP) by CaN was monitored spectrofluorometrically with excitation and emission wavelengths at $365 \mathrm{~nm}$ and $445 \mathrm{~nm}$, respectively. The fluorescence intensity was converted to the concentration of the product, 4-MU using a calibration curve as described in Materials and Methods. The hydrolysis time curve of 4-MUP assayed by CaN alone, $\mathrm{CaN}$ with equimolar $\mathrm{CaM}$, and $\mathrm{CaN}$ with equimolar $\mathrm{CaM}$ and $\mathrm{CaNp}$ were shown in green, red, and black respectively; (B) The average specific activity of CaN against 4-MUP in the absence or presence of $\mathrm{CaM}$ and $\mathrm{CaNp}$. The averaged specific phosphatase activity of $\mathrm{CaN}$ was calculated over the time period of $60 \mathrm{~min}$, as $\mu \mathrm{mol} 4-\mathrm{MU}$ produced per hour per $\mu \mathrm{g} \mathrm{CaN}$.

\subsection{Resonance Assignments of the Complex and Chemical Shift Deviation of CaM upon Binding to CaNp}

The backbone ${ }^{1} \mathrm{H}-,{ }^{13} \mathrm{C}-$, and ${ }^{15} \mathrm{~N}$-resonances of $\mathrm{CaM}$ and $\mathrm{CaNp}$ in the complex were assigned respectively from an array of triple resonance NMR experiments listed in the Materials and Methods section. All of the ${ }^{1} \mathrm{H}-,{ }^{13} \mathrm{C}$ - and ${ }^{15} \mathrm{~N}$-backbone resonances of the complex were assigned, except $\mathrm{N}$-terminal residues. The aliphatic side-chain proton and carbon chemical shifts were assigned from $\mathrm{C}(\mathrm{CO}) \mathrm{NH}, \mathrm{H}(\mathrm{CCO}) \mathrm{NH}, \mathrm{HCCH}-\mathrm{TOCSY}$, and HCCH-COSY spectra. About $95 \%$ of the proton and carbon resonances were assigned. The full resonance assignments were deposited in the BioMagBank with accession number 15624 . Figure $4 \mathrm{~A}, \mathrm{~B}$ show the $2 \mathrm{D}{ }^{1} \mathrm{H}_{-}{ }^{15} \mathrm{~N}$ HSQC spectrum of $\mathrm{CaM} / \mathrm{CaNp}$ complex and the resonances are labeled.

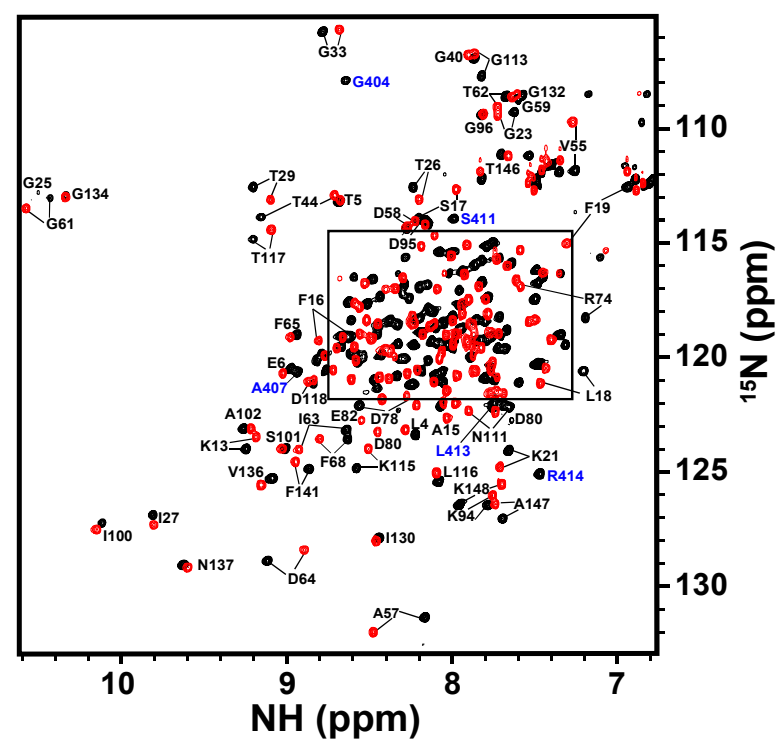

(A)

Figure 4. Cont. 


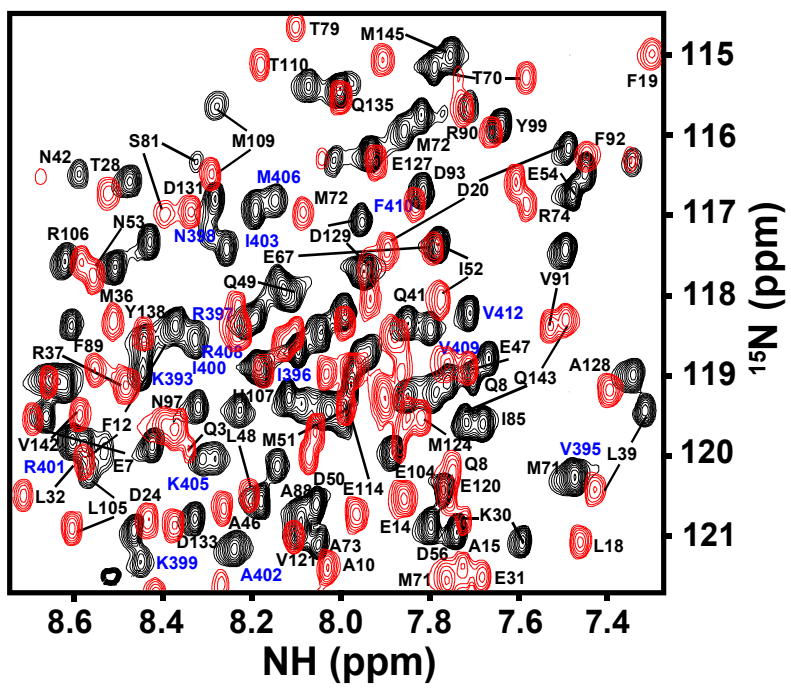

(B)

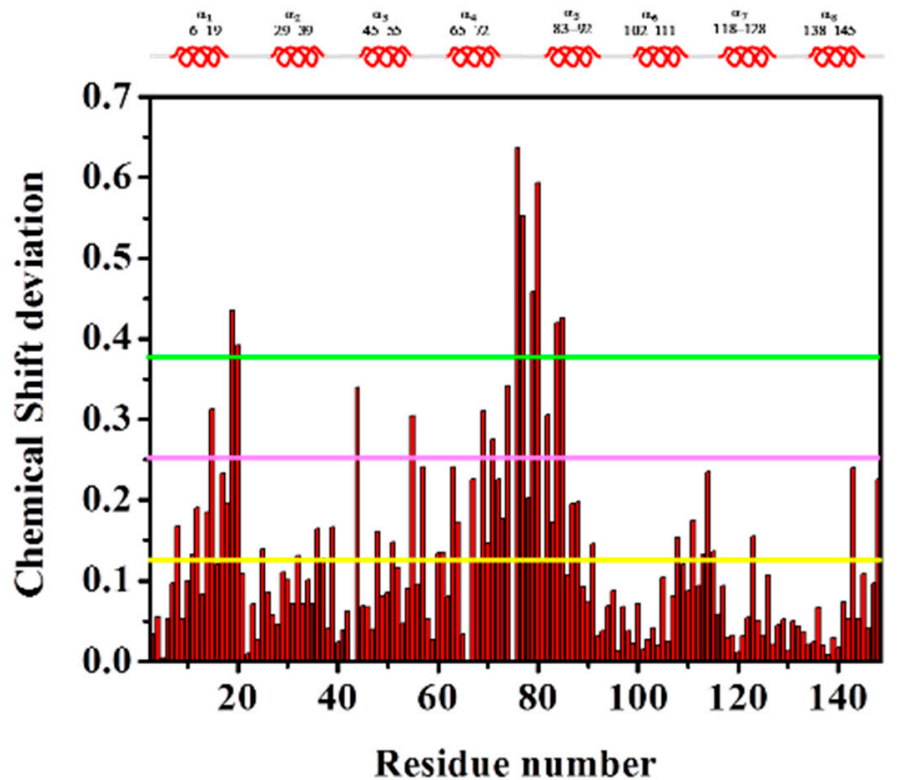

(C)

Figure 4. Two-dimensional ${ }^{1} \mathrm{H}_{-}{ }^{15} \mathrm{~N}$ HSQC spectrum of CaM in complex with CaNp and chemical shift deviation. (A) The superimposed full ${ }^{1} \mathrm{H}_{-}{ }^{15} \mathrm{~N}$ HSQC spectra of free CaM and CaM/CaNp complex. The spectra were acquired at $310 \mathrm{~K}$ in $20 \mathrm{mM} \mathrm{KCl}$, at $\mathrm{pH} 6.5$. The ${ }^{1} \mathrm{H}-{ }^{15} \mathrm{~N}$ crosspeaks of free CaM and $\mathrm{CaM} / \mathrm{CaNp}$ were shown in red, and in black, respectively. Assignments of the ${ }^{1} \mathrm{H}_{-}{ }^{15} \mathrm{~N}$ crosspeaks of $\mathrm{CaM}$ and $\mathrm{CaNp}$ are labeled in black and blue, respectively. The box region in the full spectrum was expanded and shown in (B) for the purpose of clarity; (C) The overall chemical shift perturbation, $\Delta \delta_{\text {residue }}$ of $\mathrm{CaM}$ upon association with CaNp was plotted against residue number. $\Delta \delta_{\text {residue }}$ of each residue was calculated as described in the Materials and Methods. The average of $\Delta \delta_{\text {residue }}$ for all residues of CaM upon association with papain was calculated and shown as the yellow horizontal solid line $(0.126 \mathrm{ppm})$. The magenta and green horizontal solid lines represented two- and three-fold averaged $\Delta \delta_{\text {residue, }}$ respectively. The most deviated regions with chemical shift deviation larger than three-fold of average $\Delta \delta_{\text {residue }}$ are located in helix 1 and central tether regions.

Since chemical shifts are sensitive to changes in chemical environments caused either by proximity to the interaction surface or by structural readjustments, they are frequently used as atomic resolution probes to monitor the interaction between biomolecules. We herein used chemical shift perturbation to 
map the regions with structural adjustments of CaM when associated with CaNp. The normalized chemical shift deviation of each residue, $\Delta \delta_{\text {residue }}$ was calculated as described in Materials and Methods and listed in Table S1. The normalized chemical shift deviation of CaM upon association with CaNp, $\Delta \delta_{\text {residue }}$ was plotted against residue number as shown in Figure $4 \mathrm{C}$. The average $\Delta \delta_{\text {residue }}$ for all residues of $\mathrm{CaM}$ upon association with $\mathrm{CaNp}$ was $0.126 \mathrm{ppm}$. Although the chemical shifts deviated in both $\mathrm{N}$ - and C-domains of CaM, but more in the $\mathrm{N}$-domain. The most perturbed residues of CaM with $\Delta \delta_{\text {residue }}$ larger than three folds of the averaged $\Delta \delta_{\text {residue }}$ were found in two regions, residue 19-20 (in helix 1) and residue 76 to 85 (in the inter-domain region). Our data suggested that these two regions in $\mathrm{CaM}$ undergo structural rearrangements upon association with $\mathrm{CaNp}$.

\subsection{Solution Structure of the Complex of CaM/CaNp and Its Novel Features}

The solution structures of CaM/CaNp complex were calculated using CYANA 2.1. There were 2491 NOE distance restraints used in the calculation, including 1990 and 373 restraints for CaM and $\mathrm{CaNp}$, respectively, and 128 intermolecular distance restraints between CaM and CaNp. In addition to NOE distance restraints, 72 distance restraints for hydrogen bonds, 22 distance restraints between the $\mathrm{Ca}^{2+}$ ions and the side chains of Asp and Asn residues of CaM, and 294 dihedral angle restraints were used for final calculation of the structures. An ensemble of 20 conformers with lowest restraint violations was selected for further analysis. The quality of the structural ensemble was evaluated by the program PROCHECK-NMR, in which $98.2 \%$ of the residues were in the most favored and additionally allowed regions, only $1.8 \%$ in generously allowed region, and no residues in disallowed region in the Ramachandran plot. Table 1 summarizes the input data and structure statistics.

Table 1. Structural statistics of 20 lowest-energy structures of CaM/CaNp complex.

\begin{tabular}{ll}
\hline Restraints & Number \\
\hline Intra-residue NOEs $(|\mathrm{i}-\mathrm{j}|=0)$ & 702 \\
Sequential NOEs $(|\mathrm{i}-\mathrm{j}|=1)$ & 643 \\
Medium range NOEs $(2 \leq|\mathrm{i}-\mathrm{j}| \leq 5)$ & 676 \\
Long range NOEs $(|\mathrm{i}-\mathrm{j}|>5)$ & 342 \\
Intra molecule NOEs & 128 \\
Inter molecule NOEs & 2491 \\
Total NOEs & \\
Dihedral angle restraints & $252(\phi=124, \psi=122, \chi=6)$ \\
CaM & $42(\phi=21, \psi=21)$ \\
CaNp & \\
Hydrogen Bonds & $46($ representing 23 H-bonds) \\
CaM & $26($ representing 13 H-bonds) \\
\hline CaNp & \\
\hline Restraints violations & 0 \\
Distance violations & 0 \\
van der Waals violations & 0 \\
Angle violations & \\
\hline Ramachandran analysis & 92.6 \\
Residues in most favored regions (\%) & 5.6 \\
Residues in additional allowed regions (\%) & 1.9 \\
Residues in generously allowed regions (\%) & 0.0 \\
Residues in disallowed regions (\%) & \\
\hline RMSD from mean structure (A) & $0.66 \pm 0.24$ \\
Backbone & $1.14 \pm 0.28$ \\
Heavy atoms & \\
\hline
\end{tabular}

The final refined ensembles of 20 lowest energy structures have been deposited into the protein data bank (PDB) with accession code 2JZI. The best-fit superposition of the 20 best backbone structures of CaM/CaNp complex and black respectively is shown in Figure 5A, the ensemble of 20 structures has root mean square deviations (RMSD) of $0.66 \AA$ for backbone and $1.14 \AA$ for all atoms (residue 5 to 
145 for CaM and residue 392 to 413 for CaNp). The amino (residue 1 to 4), and carboxyl (residue 146 to 148) termini of CaM, the linker region connecting the two homologous domains of CaM (residue 73-81) are not well-defined. Two ribbon diagrams of the averaged structure in different orientations are shown in Figure 5B,C. The complex structure shows an ellipsoidal shape with eight $\alpha$ helices $\left(\alpha_{1}-\alpha_{8}\right)$ of CaM wrapping around the CaNp helix.

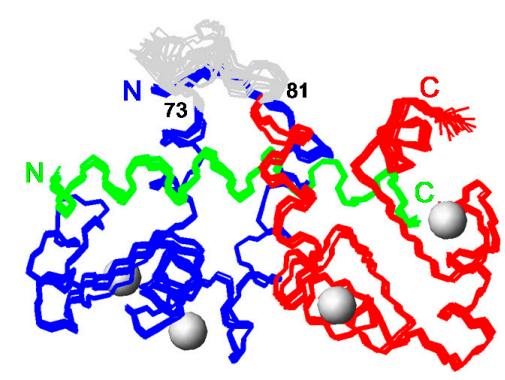

(A)

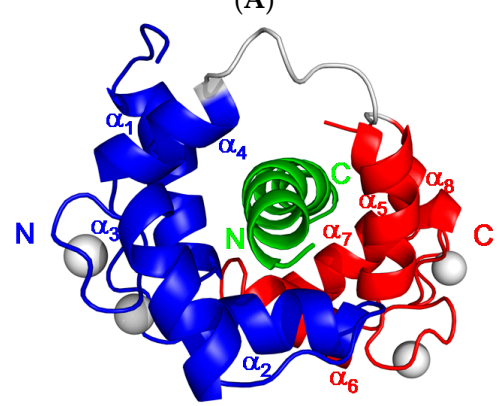

(C)

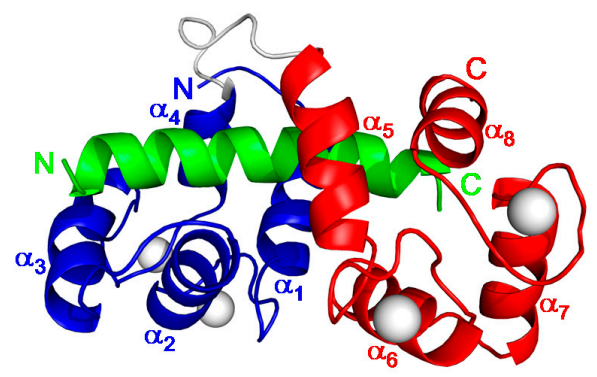

(B)

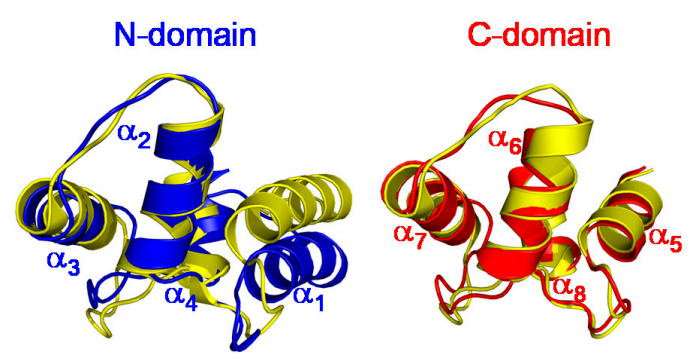

(D)

Figure 5. Solution structure of CaM in complex with CaNp. (A) The ensemble of 20 best structures of the complex of CaM and CaNp is superimposed. The backbone structures of the N-domain, C-domain, and tether region of $\mathrm{CaM}$ are colored coded in blue, red, and grey respectively. $\mathrm{Ca}^{2+}$ ions are shown as grey spheres. The CaNp is colored coded in green. The $\mathrm{N}$ - and C-termini of CaM and CaNp are labeled as $\mathrm{N}$ and $\mathrm{C}$ respectively; (B) The ribbon representation of CaM/CaNp complex structure. The complex structure shows an ellipsoidal shape with $8 \alpha$-helices $\left(\alpha_{1}-\alpha_{8}\right)$ of CaM wrapping the $\mathrm{CaNp}$ helix; (C) Side view of the ribbon representation of CaM/CaNp complex structure. CaNp shows a curved helical conformation centered at the residue $\mathrm{Gly}^{404}$; (D) The structural changes of the two domains of CaM upon binding to CaNp. The structure of free CaM (in yellow) superimposed with the structure of $\mathrm{CaM}$ when associated with $\mathrm{CaNp}$. The $\mathrm{N}$-domain and $\mathrm{C}$-domain of $\mathrm{CaM}$ in the bound form is colored in blue and red respectively. N-domain of CaM, especially helix I $\left(\alpha_{1}\right)$ undergoes larger structural changes upon association with $\mathrm{CaNp}$, whereas $\mathrm{C}$-domain of $\mathrm{CaM}$ remains unchanged.

As compared to the backbone of free CaM [9], the C-terminal domain of CaM (residue 84-145, C-domain) remains mostly unchanged with the RMSD value $1.0 \AA$ upon association with CaNp as shown in Figure 5D. However, the N-terminal domain (residue 5-72, N-domain) exhibits a much larger conformational change upon association with CaNp, with the RMSD value $2.3 \AA$, helix I $\left(\alpha_{1}\right)$ is pushed away from helices II to IV $\left(\alpha_{2}\right.$ to $\left.\alpha_{4}\right)$. Besides the displacement of $\alpha_{1}$, the inter-domain linker region, from residue 73 to 81 of CaM unwinds to a flexible loop. The large structural change in the regions of $\alpha_{1}$ and inter-domain linker of CaM is in accord with the chemical shift deviation data. Upon associated with $\mathrm{CaM}, \mathrm{CaNp}$ folds up to a $\alpha$-helical structure from random coil in the region of residue 392 to 413 . Unlike the most determined CaM/peptide structures, the structure of bound CaNp consists of two helical segments, N-helix and C-helix, separated by the tether residue Gly ${ }^{404}$ with a $17^{\circ}$ inter-helical angle. The curvature in center of the helical $\mathrm{CaNp}$ may reduce the stretching force between the two domains of CaM to accommodate the longest binding helix in CaM target sequences.Extensive intermolecular NOEs between side chains of $\mathrm{CaNp}$ and $\mathrm{CaM}$ were observed 
from the isotope-separated NOESY-HSQC spectrum and summarized in Figure 6A. The spacing and position of bulky hydrophobic residues of the target sequence are important features in characterizing the binding modes of CaM and target sequences. The most abundant NOE pairs were found from two major hydrophobic residues, $\mathrm{Ile}^{396}$, and Leu ${ }^{413}$ and two minor hydrophobic residues, Ile ${ }^{400}$, and Phe ${ }^{410}$ which exhibit a novel 1-5-15-18 binding type. The intermolecular NOE pairs were found between the residues in the N-helix of CaNp and the N-domain of CaM, and between C-helix of CaNp and the C-domain of CaM. Apparently, the binding orientation of CaNp with respect to the two globular domains of $\mathrm{CaM}$ is opposite to those structures in the prototypical 1-14 and in 1-10 binding types. Instead, the binding orientation of CaNp with respect to CaM is similar to the CaMKK peptide in the 1-16 binding mode.

As shown in Figure 6B, the hydrophobic surface of N-domain of CaM was occupied by the side chains of $\mathrm{Ile}^{396}$ and Ile $\mathrm{e}^{400}$ of CaNp which located in the N-helix of CaNp. These two anchor residues of CaNp form hydrophobic contacts with numerous hydrophobic residues $\left(\mathrm{Leu}^{32}, \mathrm{Leu}^{48}, \mathrm{Ile}^{52}, \mathrm{Val}^{55}\right.$, $\mathrm{Ile}^{63}$, and Phe ${ }^{68}$ ) and three methionine residues $\left(\mathrm{Met}^{51}, \mathrm{Met}^{71}\right.$, and $\mathrm{Met}^{72}$ ) in the N-domain of CaM. On the other hand, the hydrophobic surface of C-domain of CaM was in close contacts with the side chains of Phe $\mathrm{P}^{410}$, and Leu ${ }^{413}$ of CaNp which are located in the C-helix of CaNp.

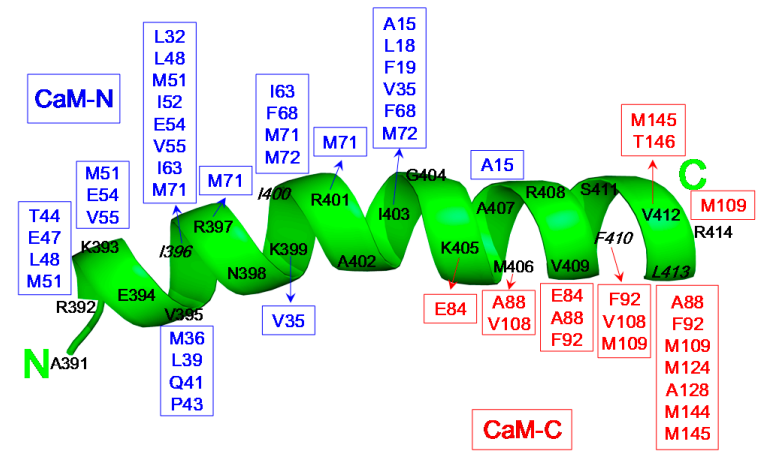

(A)

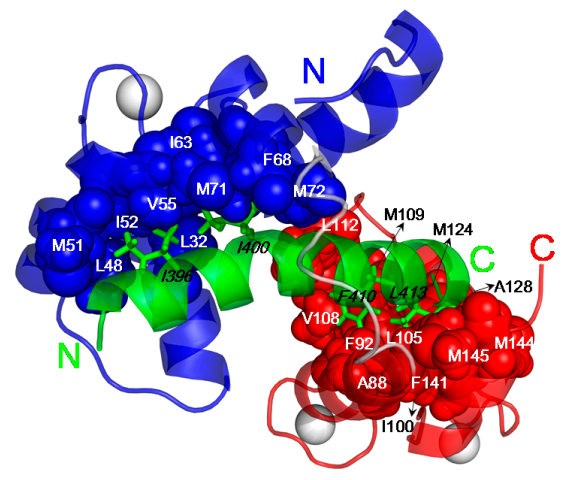

(B)

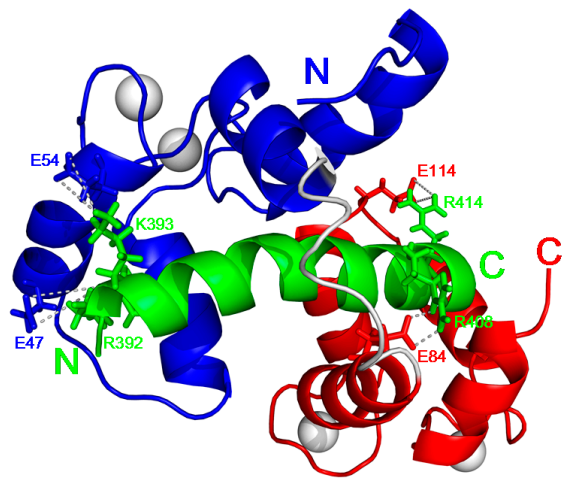

(C)

Figure 6. Intermolecular interactions between CaM and CaNp. (A) Summary of the observed NOEs between $\mathrm{CaM}$ and $\mathrm{CaNp}$. CaNp is shown as a green helical ribbon. Interacting residues in $\mathrm{N}$-domain and C-domain of CaM are labeled in blue and red, respectively; (B) The hydrophobic interactions between CaM and CaNp. Two intermolecular hydrophobic clusters were found in the complex of $\mathrm{CaM} / \mathrm{CaNp}$. Bulky side chains of $\mathrm{Ile}^{396}$ and $\mathrm{Ile}^{400}$ of CaNp (shown in green sticks) anchored in the hydrophobic pocket of N-domain of CaM (shown in blue spheres). Bulky side chains of Phe ${ }^{410}$, and $\mathrm{Leu}^{413}$ of $\mathrm{CaNp}$ (shown in green stick) anchored in the hydrophobic pocket of C-domain of CaM (shown in red spheres); (C) The potential electrostatic interactions between the negatively charged residues of $\mathrm{CaM}\left(\mathrm{Glu}^{47}, \mathrm{Glu}^{54}, \mathrm{Glu}^{84}\right.$, and $\left.\mathrm{Glu}^{114}\right)$ and the positively charged residues of $\mathrm{CaNp}\left(\mathrm{Arg}^{392}\right.$, $\mathrm{Lys}^{393}, \mathrm{Arg}^{408}$, and $\mathrm{Arg}^{414}$ ) are shown. 
Interestingly, mediator residue $\mathrm{Ile}^{403}$ located in the middle of CaNp is in close contacts with the hydrophobic side chains from both domains of CaM including Ala ${ }^{15}$, Leu ${ }^{18}, \mathrm{Phe}^{19}, \mathrm{Val}^{35}$, Phe ${ }^{68}$, and $\mathrm{Met}^{72}$ from N-domain and Leu ${ }^{112}$ from C-domains of CaM. The intermolecular hydrophobic interactions between $\mathrm{Ile}^{403}$ of CaNp and $\mathrm{Ala}^{15}$, $\mathrm{Leu}^{18}$, $\mathrm{Phe}^{19}$, located in the helix I of CaM explain the large displacement of $\alpha_{1}$ respective to the rest of $\mathrm{N}$-domain when associated with $\mathrm{CaNp}$ and in accord with the chemical shift deviation data. In addition to the hydrophobic interactions, the electrostatic complementarity between $\mathrm{CaM}$ and $\mathrm{CaNp}$ also plays an important role in the binding affinity and the orientation of $\mathrm{CaNp}$ to $\mathrm{CaM}$. The intermolecular electrostatic interactions involve the positively charged Arg/Lys residues of CaNp and the negatively charged Glu residues of CaM. Four intermolecular electrostatic pairs, including $\mathrm{Arg}^{392} / \mathrm{Glu}^{47}$, $\mathrm{Lys}^{393} / \mathrm{Glu}^{54}, \mathrm{Arg}^{408} / \mathrm{Glu}^{84}$, and $\mathrm{Arg}^{414} / \mathrm{Glu}^{114}$ between $\mathrm{CaNp}$ and $\mathrm{CaM}$ were found to stabilize the complex structure (Figure 6C).

\subsection{Comparison of the Solution Structure of CaM/CaNp to Other CaM/Target Peptide Structures}

In order to show the novel features of $\mathrm{CaM} / \mathrm{CaNp}$ complex, the representative structures of $\mathrm{CaM} /$ target peptide complexes in different CaM-recognition modes including 1-14, 1-16, and 1-18 binding types were compared to the solution structure of CaM/CaNp. The ribbon diagrams of prototypical structures of $\mathrm{CaM}$ associated with the target peptide from myosin light chain kinase (PDB ID: 2BBM), CaM-dependent kinase kinase (PDB ID: 1CKK), plasma membrane calcium pump (PDB ID: 2KNE), and calcineurin (PDB ID: 4Q5U in crystal form; 2JZI in solution form) are shown in Figure 7. The backbone conformation of each domain of CaM in 2JZI resembles to free CaM and other $\mathrm{CaM}$ /target peptide structures including 2BBM, 1CKK, 2KNE, and 4Q5U. The backbone RMSD value is in the range of 1.0-1.8 $\AA$ for C-domain (residue 82-145), and 2.1-2.5 $\AA$ for N-domain (residue 5-72), respectively. The larger RMSD in N-domain of CaM is caused by the displacement of helix I upon binding to CaNp. If the coordinates of helix I are excluded, the RMSD for N-domain (residue 28-72) is greatly reduced to 1.2-1.8 $\AA$. Other novel features of the solution structure of CaM/CaNp complex include the conformation of bound $\mathrm{CaNp}$, and the relative position of the two globular domains. Different from the target peptides in the previous determined CaM/peptide complex structures, bound CaNp in 2JZI forms a novel V-shaped helical structure with a kink at the residue Gly ${ }^{403}$ as shown in Figure 7E. The relative position of the two homologous domains of CaM in CaM/target peptide complexes is in a 'C2-like' symmetry except the solution structure of CaM/CaNp complex. The bend in the bound $\mathrm{CaNp}$ helix causes a certain deviation of the relative orientation of the two homologous CaM domains from C2-like symmetry. In order to characterize the relative position of the two homologous domains in different CaM/target peptide complexes, a screw rotation axis passing through the $\alpha$-helical axis of the target peptide is chosen (Figure 7). To superimpose the N-domain onto $\mathrm{C}$-domain of $\mathrm{CaM}$ along this screw axis, a roughly $\mathrm{C} 2$ symmetry is found in the structures of 2BBM, $1 \mathrm{CKK}, 2 \mathrm{KNE}$, and 4Q5U. However, in the case of CaM/CaNp structure in solution form, an additional $17^{\circ}$ rotation angle had to be applied.

There are differences between the structures of CaM/CaNp in solution form (2JZI) and in crystal form (4Q5U). The crystal structure of CaM/CaNp in 4Q5U can be classified as 1-15 CaM-target binding mode according to the spacing between the two major hydrophobic anchors in the target sequence; however, the solution structure of 2JZI shows 1-18 CaM-target binding mode. The relative orientation of the helical target sequence respective to $\mathrm{CaM}$ is also different. In the crystal structure of 4Q5U, the hydrophobic anchors in the N-terminal and C-terminal of target sequence were engulfed in the hydrophobic pocket of the $\mathrm{C}$ - and N-terminal domain of CaM, respectively. On the contrary, the orientation of the helical target peptide with respect to the two domains of CaM in solution is opposite to that in crystal. In addition, the ionic interactions between the target peptide and CaM are different. In the crystal structure 4Q5U, four intermolecular electrostatic pairs, including Arg392/Glu114, Lys393/Glu127, Arg408/Glu84, and Arg414/Glu47 between CaNp and CaM were found. In the solution structure of 2JZI, four intermolecular electrostatic pairs, including Arg392/Glu47, Lys393/Glu54, Arg408/Glu84, and Arg414/Glu114 were found. 
(A) 2BBM $1-14$
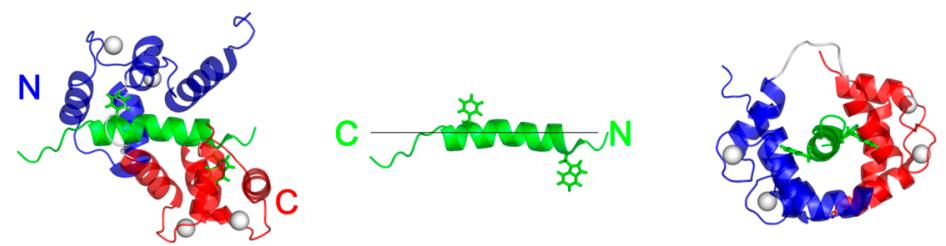

(B) $1 \mathrm{CKK}$
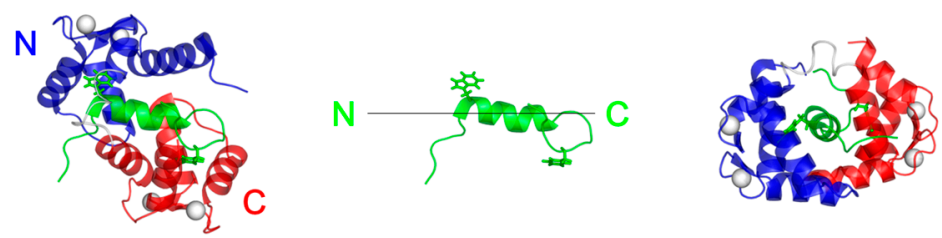

(C) $2 \mathrm{KNE}$
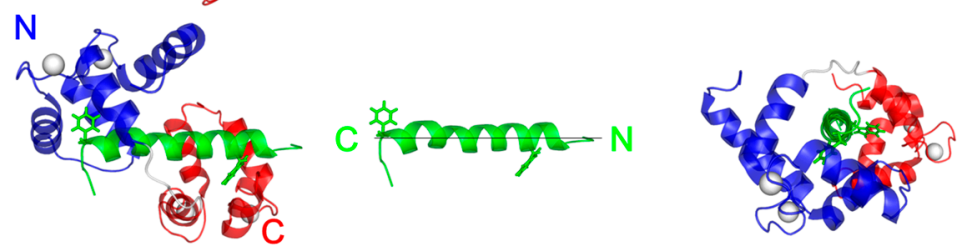

(D) 4 Q5U
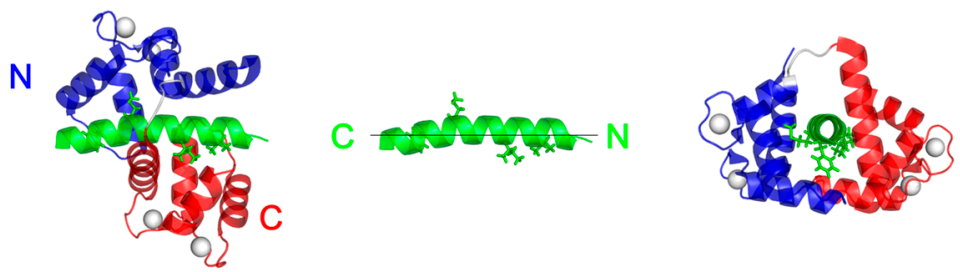

(E) $2 \mathrm{JZI}$

$1-18$
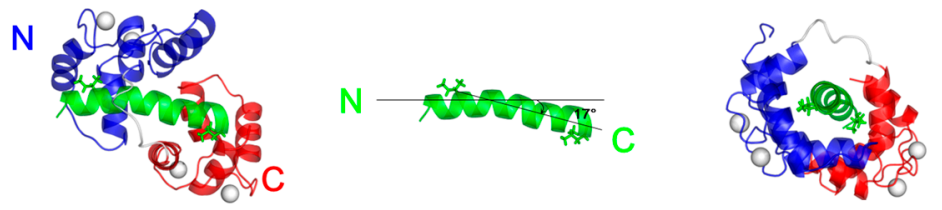

Figure 7. Comparison of relative orientation of $\mathrm{N}$ - and C-domain of CaM upon binding to different target peptides. (A) CaM and the target sequence of skeletal muscle myosin light chain kinase (PDB 2BBM); (B) CaM and the target sequence of CaM-dependent kinase kinase (PDB 1CKK); (C) CaM and the target sequence of plasma membrane calcium pump (PDB 2KNE); (D) CaM and CaNp in crystal form (PDB 4Q5U); (E) CaM and CaNp in solution form (PDB 2JZI). In order to compare the relative position of the C-domain of CaM in the structure of 2JZI, 2BBM, 1CKK, 2KNE, and 4Q5U, the position of the N-domain of CaM in these structures was fixed.

\subsection{The Activation Processes of $\mathrm{CaN}$ by CaM}

The most accepted model for the activation of $\mathrm{CaN}$ by $\mathrm{Ca}^{2+}$ and $\mathrm{CaM}$ includes several sequential changes in conformations $[49,66]$. In summary, the conformational change is triggered by occupancy of calcium ions to the low affinity sites of CaN-B subunit which causes the dissociation of the CaM target domain from the CaN-B binding domain. Subsequently, CaM recognizes this target region and leads to the displacement of auto-inhibitory domain (AID) from the active site and full activation. Although this activation model is in accord with most biochemical and biophysical results, there is limited structural information reported to prove the details of the structural changes in the activation process. Here, we reported the solution structure of $\mathrm{CaM} / \mathrm{CaNp}$ to put back the missing pieces for the activation action of $\mathrm{CaM}$ on $\mathrm{CaN}$. Figure 8 shows a schematic diagram for the activation of $\mathrm{CaN}$ combining previous models and our data reported here. The regulatory domain of CaN-A subunit is mostly unstructured and invisible in the crystal structures in the region ranged from residue 369 to 521, only a short AID helix located near the active site was found (PDB ID: 1AUI) (Figure 8A). The hydrophobic surface of CaM recognizes the hydrophobic anchors in the target sequence in $\mathrm{CaN}$, and further transforms the target sequence to mostly helical structure. Based on our structural and 
chemical shift deviation data (Figures $4 \mathrm{C}$ and 5D), we found much less structural/chemical changes in the C-domain of CaM upon association with the target sequence of $\mathrm{CaN}$.

Since the two domains of CaM exhibit subtle differences in $\mathrm{Ca}^{2+}$ affinity, in the presence of limited concentration of calcium, here only the high affinity $\mathrm{Ca}^{2+}$-binding sites in $\mathrm{C}$-domain of $\mathrm{CaM}$ are saturated. We therefore propose that the hydrophobic interactions between the $\mathrm{Ca}^{2+}$-saturated $\mathrm{C}$-domain of $\mathrm{CaM}$ and the $\mathrm{C}$-terminal half of the target sequence of $\mathrm{CaN}$, which contains more hydrophobic residues provide the driving force for the initial recognition. Subsequently, the target sequence of $\mathrm{CaN}$ undergoes a conformational transition from unstructured to helical and further improves its structural complementarity and binding affinity to CaM. Meanwhile, upon binding with the target sequence, CaM also undergoes conformational adjustment and the affinity to $\mathrm{Ca}^{2+}$ greatly increases, leading to the final structure of the full $\mathrm{Ca}^{2+}$-saturated $\mathrm{CaM} / \mathrm{CaNp}$ complex in an ellipsoidal shape (Figure 8B). Finally, the charge distribution on surfaces of CaM/CaNp complex and AID is mostly negatively charged, especially on the surface of the C-domain of CaM/CaNp complex. The electrostatic repulsion between CaM/CaNp complex and AID may result in the displacement of AID from active site to full activation (Figure 8C).

(A)

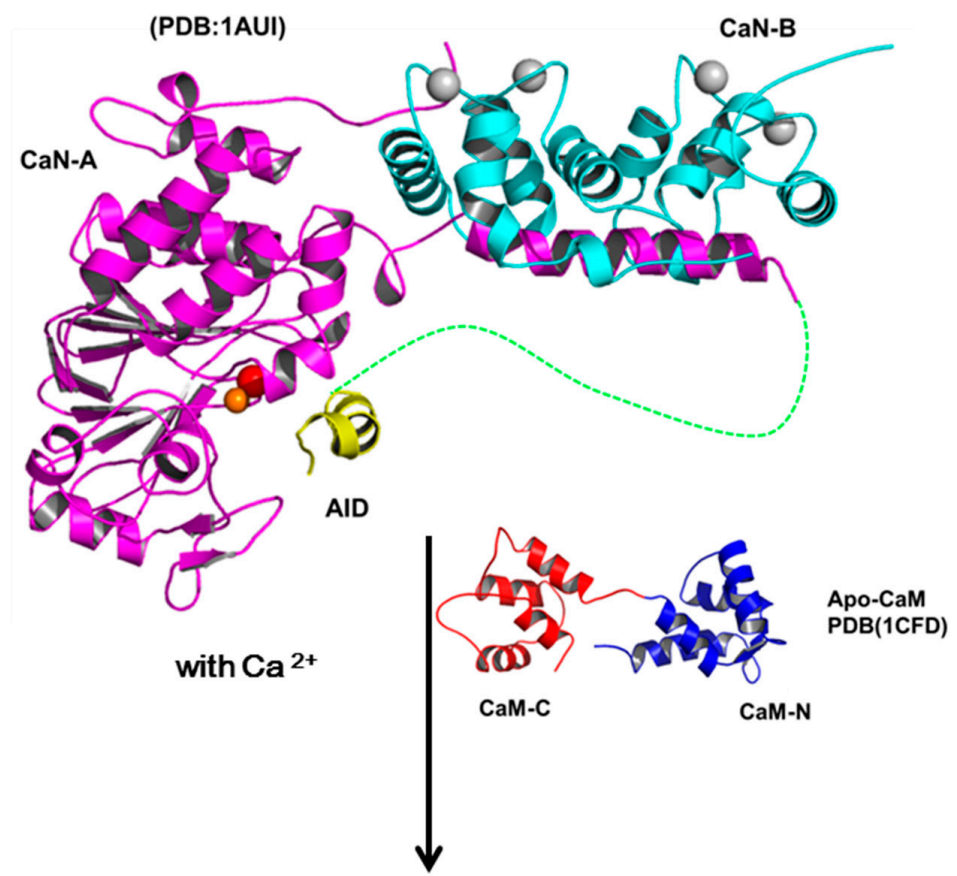

(B)

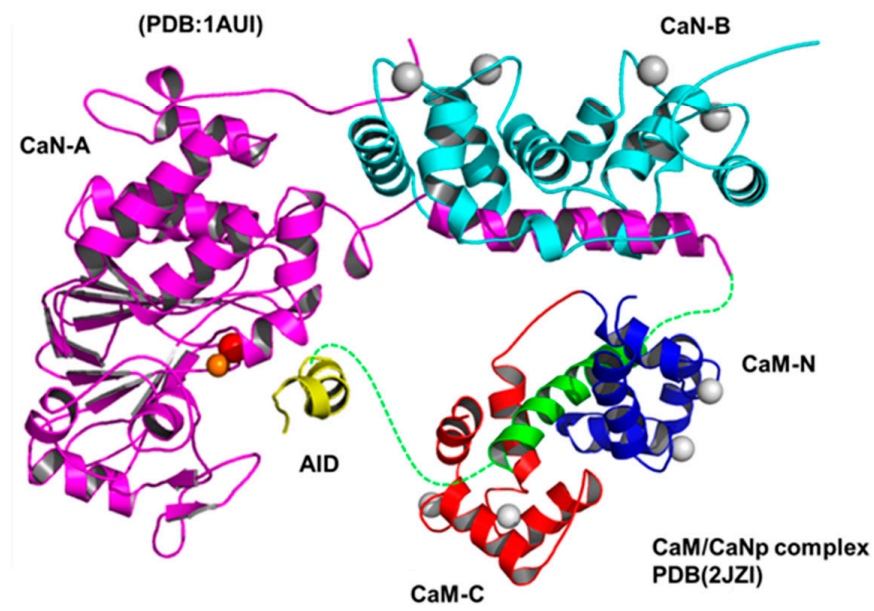

Figure 8. Cont. 
(C)

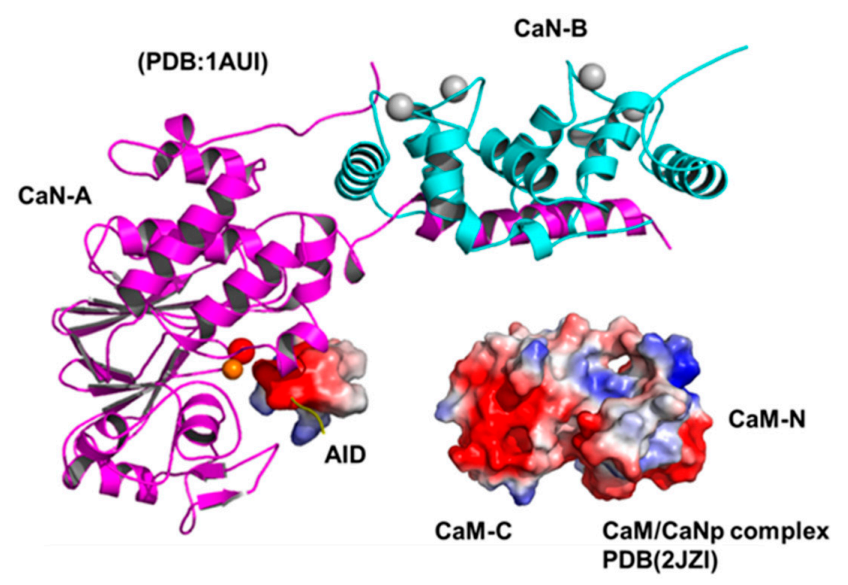

Figure 8. The schematic diagram of the activation processes of CaN. (A) Ribbon representation of the structure of human CaN (1AUI). The CaN-B is colored coded in cyan. The catalytic domain, AID of $\mathrm{CaN}-\mathrm{A}$ is colored coded in magenta and yellow. The region connecting the BBD to AID is invisible in the electron density map (draw in green dashed line). (B) The complex formation of CaM and the target sequence of CaN. (C) The charge distribution of CaM/CaNp complex and AID. Positive and negative electrostatic charge is colored in blue and red, respectively. Both surfaces are mostly negatively-charged, especially in the C-domain of CaM/CaNp complex. The electrostatic repulsion between CaM/CaNp complex and AID may result in the displacement of AID from active site to full activation.

\section{Materials and Methods}

\subsection{Cloning, Expression and Purification of CaM and CaNp}

The cDNA of chicken CaM was subcloned into a modified pET29c expression vector. The construct was verified by DNA sequencing, and then transformed into E. coli BL21 (DE3) host and expressed. The recombinant $\mathrm{CaM}$ was purified by a hydrophobic, phenyl sepharose column. ${ }^{13} \mathrm{C},{ }^{15} \mathrm{~N}$-labeled CaM was expressed in a modified M9 medium with ${ }^{15} \mathrm{NH}_{4} \mathrm{Cl}$ and ${ }^{13} \mathrm{C}$-glucose as sole ${ }^{15} \mathrm{~N}$ and ${ }^{13} \mathrm{C}$ sources. The gene coding for the CaM-CaNp hybrid molecule was synthesized by a series of PCR reactions. The $5^{\prime}$-end primer contained an NdeI restriction enzyme cleavage site, and the 3 '-end primers contained the sequences coded $\mathrm{CaNp}$ followed by stop condon and an XhoI restriction enzyme cleavage site. The PCR-amplified CaM-CaNp hybrid gene was then subcloned into a modified pET29c expression vector. The construct was verified by DNA sequencing of the entire coding region and the cloning sites. The recombinant CaM-CaNp hybrid molecule comprises the sequences of CaM, CaM-binding domain of $\mathrm{CaN}\left(\mathrm{CaNp},{ }^{391}\right.$ ARKEVIRNKIRAIGKMARVFSVLR $\left.{ }^{414}\right)$, and a factor Xa cleavage site (IEGR) in between. The plasmid coding for CaM-CaNp hybrid molecule was transformed into E. coli strain BL21 (DE3). The transformed cells were grown at $37^{\circ} \mathrm{C}$ to $1 \mathrm{OD}_{600 \mathrm{~nm}}$ in LB medium, $0.4 \mathrm{mM}$ IPTG was then added to induce gene expression. The harvest cells were resuspended in $25 \mathrm{mM}$ Tris- $\mathrm{HCl}$ buffer pH 8.0, 1 mM EDTA, and 0.1 mM PMSF, and disrupted by sonication. After the cell debris had been pelleted by centrifugation, the whole cell lysate containing CaM-CaNp hybrid molecules were separated by a Q-Sepharose ion exchange column, followed by a size exclusive column (Hiload 16/60 Superdex 75, GE Healthcare, Wauwatosa, WI, USA). The purified CaM-CaNp hybrid molecules ran as a single band in SDS-PAGE. The linker (IEGR) in between the sequences of CaM and CaNp was then cleaved by factor Xa according to the instructions of manufacturer (GE Healthcare). CaNp was separated from CaM by ultrafiltration with an YM-10 membrane (Millipore-Sigma, St. Louis, MO, USA) at $\mathrm{pH} 2$. The purified CaNp ( $>95 \%)$ was confirmed by analytical HPLC and mass spectrometry. The ${ }^{13} \mathrm{C}-{ }^{15} \mathrm{~N}-$ labeled CaM-CaNp hybrid molecules were expressed in a modified M9 medium with ${ }^{13} \mathrm{C}$-glucose and ${ }^{15} \mathrm{NH}_{4} \mathrm{Cl}$ as sole ${ }^{13} \mathrm{C}$ and ${ }^{15} \mathrm{~N}$ sources (Cambridge Isotope Inc., Tewksbury, MA, USA). The ${ }^{13} \mathrm{C}-15 \mathrm{~N}$-labeled $\mathrm{CaNp}$ was obtained using the same separation procedures as non-labeled $\mathrm{CaNp}$. 


\subsection{Purification of CaN Enzyme from Bovine Brain}

CaN enzyme was isolated from bovine brain cerebra as previously described with modifications [67]. Bovine brain cerebra were obtained fresh from a local abattoir and stored at $-20^{\circ} \mathrm{C}$ until needed. The $\mathrm{CaN}$ enzyme was purified by three steps including Affi-gel blue (BioRad, Hercules, CA, USA), CaM-sepharose affinity, and mono-Q anion exchange (GE Healthcare) chromatography. Bovine brain extract was loaded onto Affi-gel blue, and eluted with buffer A ( $50 \mathrm{mM}$ Tris- $\mathrm{HCl}, 3 \mathrm{mM}$ $\mathrm{MgSO}_{4}, 0.5 \mathrm{mM}$ DTT, $1 \mathrm{mM}$ EDTA, and $0.02 \% \mathrm{NaN}_{3}$ at $\mathrm{pH} 7.8$ ). Fractions containing CaN enzyme were pooled and loaded onto a CaM-Sepharose affinity column which had equilibrated with buffer $\mathrm{B}$ (50 mM Tris- $\mathrm{HCl}, 3 \mathrm{mM} \mathrm{MgSO}_{4}, 0.5 \mathrm{mM} \mathrm{DTT}, 0.1 \mathrm{mM} \mathrm{CaCl}_{2}$, and $0.02 \% \mathrm{NaN}_{3}$ at $\mathrm{pH} 7.8$ ). The affinity column was extensively washed with buffer B supplemented with $0.5 \mathrm{M} \mathrm{NaCl}$ and then eluted with buffer A. The pooled fractions from the affinity column were then loaded onto a mono-Q column, eluted with a linear $\mathrm{NaCl}$ gradient. The purity of $\mathrm{CaN}$ enzyme was higher than $80 \%$ by SDS-PAGE with two major bands, $60 \mathrm{kDa}$ (CaN A subunit) and $20 \mathrm{kDa}$ (CaN B subunit). A minor band, the partial proteolytic fragment of CaN A subunit with $48 \mathrm{kDa}$ was also observed. The purified CaN enzyme was stored with $50 \%$ glycerol at $-20^{\circ} \mathrm{C}$.

\subsection{Activity Assay of $\mathrm{CaN}$}

Phosphatase activities of CaN were assayed fluorometrically using 4-methylumbelliferyl-phosphate (4-MUP, Sigma, St. Louis, MO, USA) as the substrate. The basal activity of CaN was determined using $200 \mu \mathrm{M}$ substrate and $25 \mathrm{nM}$ enzyme CaN in the buffer containing $50 \mathrm{mM}$ Tris $\mathrm{pH}$ 8.6, 0.5 mM DTT, $1 \mathrm{mM}$ $\mathrm{MgCl}_{2}$, and $0.3 \mathrm{mM} \mathrm{CaCl}_{2}$ at $25^{\circ} \mathrm{C}$. The CaM-dependent activation of the activity of CaN was measured by the addition of $25 \mathrm{nM} \mathrm{CaM}$ to the same reaction conditions described above. Fluorescence data were recorded using an Aminco Bowman (ABII) spectrofluorometer (Thermo Spectronic Inc., Rochester, NY, USA). The formation of the product, 4-MU, was monitored with excitation wavelength at $365 \mathrm{~nm}$, and emission wavelength at $445 \mathrm{~nm}$. Data were collected over a time course of 75 mins. A calibration curve was generated by measuring the fluorescence intensities of solutions containing various concentrations of 4-MU under the same assay conditions. The fluorescence intensities of the test samples were converted to the 4-MU concentration according to the calibration curve. The phosphatase activity of $\mathrm{CaN}$ is defined as $\mu$ mol 4-MU produced per hour per $\mu \mathrm{g}$ CaN used.

\subsection{NMR Sample Preparation}

The NMR sample was prepared in the following procedures, $10 \mathrm{mg}$ CaM was dissolved into $1 \mathrm{~mL}$ solution containing $90 \% \mathrm{H}_{2} \mathrm{O} / 10 \% \mathrm{D}_{2} \mathrm{O}, 10 \mathrm{mM} \mathrm{CaCl}_{2}, 20 \mathrm{mM} \mathrm{KCl}, 0.02 \% \mathrm{NaN}_{3}$, at pH 6.5. The appropriate amount of CaNp stock solution $(2 \mathrm{mM})$ was added gradually into the CaM solution with gentle mixing to ensure the $\mathrm{CaM} / \mathrm{CaNp}$ complex formation. The solution was then concentrated by Centricon-10 ultrafiltration apparatus (Millipore Inc.) to a final concentration of CaM/CaNp complex about $1.1 \mathrm{mM}$. The excess CaNp molecules were also removed by this procedure. The final $\mathrm{CaM} / \mathrm{CaNp}$ complex sample solution was transferred to $5 \mathrm{~mm}$ Shigemi NMR tubes (Shigemi Co., Tokyo, Japan) for recording NMR spectra.

\subsection{NMR Spectroscopy}

The NMR experiments were performed at $310 \mathrm{~K}$ on an Avance II $600 \mathrm{MHz}$ spectrometer (Bruker BioSpin, Rheinstetten, Germany) at National Dong Hwa University, or a $800 \mathrm{MHz}$ spectrometer (Bruker BioSpin, Rheinstetten, Germany) at the High-Field Biomacromolecular NMR Core Facility, Academia Sinica. All spectra were processed by TOPSPIN on Linux workstations. All the chemical shifts were referenced to internal DSS in ${ }^{1} \mathrm{H}$ dimension, and calibrated using the gyromagnetic ratio $0.101329118\left({ }^{15} \mathrm{~N} /{ }^{1} \mathrm{H}\right)$ in ${ }^{15} \mathrm{~N}$ dimension and $0.251449530\left({ }^{13} \mathrm{C} /{ }^{1} \mathrm{H}\right)$ in ${ }^{13} \mathrm{C}$ dimension [68]. Backbone and side chain assignments of $\mathrm{CaM}$ and $\mathrm{CaNp}$ in the complex form were assigned separately by the NMR spectra obtained from ${ }^{13} \mathrm{C}-15 \mathrm{~N}$-labeled CaM associated with non-labeled 
CaNp and non-labeled CaM associated with ${ }^{13} \mathrm{C}^{15} \mathrm{~N}$-labeled CaNp samples. Backbone and side chain sequential assignments were obtained using the following standard experiments: $2 \mathrm{D}^{15} \mathrm{~N}-{ }^{1} \mathrm{H}-\mathrm{HSQC}$, 2D ${ }^{13} \mathrm{C}-{ }^{1} \mathrm{H}-\mathrm{HSQC}$, 3D HNCO, 3D HN(CA)CO, 3D HNCA, 3D CBCANH, 3D CBCA(CO)NH, 3D CC(CO)NH, 3D HBHA(CBCACO)NH, 3D HCC(CO)NH, 3D HCCH-COSY and 3D HCCH-TOCSY. The assignments of aromatic side chains in $\mathrm{CaM} / \mathrm{CaNp}$ complex were obtained by homonuclear 2D spectra including DQF-COSY, TOCSY, and 3D ${ }^{15} \mathrm{~N}$-separated NOESY-HSQC spectra. The side chain amide groups of Asn and Gln were assigned on the basis of NOEs between ${ }^{1} \mathrm{H}_{\gamma}$ or ${ }^{1} \mathrm{H}_{\delta}$ and ${ }^{1} \mathrm{H}_{\beta}$ observed in the 3D ${ }^{15} \mathrm{~N}$-separated NOESY-HSQC spectrum. The NOE distance restraints were obtained from 3D ${ }^{15} \mathrm{~N}$-separated and ${ }^{13} \mathrm{C}$-separated NOESY-HSQC spectra of the ${ }^{13} \mathrm{C}^{15} \mathrm{~N}$-labeled CaM associated with ${ }^{13} \mathrm{C}^{15} \mathrm{~N}$-labeled CaNp sample.

\subsection{Structure Calculation and Analysis}

NOE distance restraints were derived from 3-dimensional ${ }^{15} \mathrm{~N}$-edited NOESY-HSQC (mixing time 100 and $150 \mathrm{~ms}$ ) and ${ }^{13} \mathrm{C}$-edited NOESY-HSQC (100 ms) spectra. The NOE crosspeaks were picked and quantified by peak-picking algorithm in Aurelia. The NOE peak intensities were converted into upper distance bounds using CALIB module in the torsional angle dynamics program CYANA [69]. Intramolecular NOE distance restraints of $\mathrm{CaM}$ and $\mathrm{CaNp}$ were primarily deduced from $3 \mathrm{D}{ }^{15} \mathrm{~N}$ and ${ }^{13} \mathrm{C}$-edited NOESY-HSQC spectra of ${ }^{13} \mathrm{C},{ }^{15} \mathrm{~N}$-labeled CaM in complex with unlabeled CaNp, and unlabeled CaM in complex with ${ }^{13} \mathrm{C},{ }^{15} \mathrm{~N}$-labeled CaNp sample, respectively. Intermolecular NOE restraints were obtained and confirmed from ${ }^{15} \mathrm{~N}$ - and ${ }^{13} \mathrm{C}$-edited NOESY-HSQC spectra of both ${ }^{13} \mathrm{C}^{15} \mathrm{~N}$-labeled CaM and CaNp. The backbone dihedral angles $(\phi$ and $\psi)$ restraints were derived by chemical shifts of ${ }^{13} \mathrm{C}^{\alpha},{ }^{13} \mathrm{C}^{\beta},{ }^{13} \mathrm{CO},{ }^{1} \mathrm{H}^{\alpha}$, and ${ }^{15} \mathrm{~N}$ nuclei using the program TALOS [70,71]. Hydrogen bond restraints were assigned between slowly exchanging amide protons and their respective carbonyl acceptors deduced from the NOE data in combination with the secondary structure information predicted from CSI [72]. Distance restraints between the $\mathrm{Ca}^{2+}$ ions and the side chain oxygen atoms of Asp and Asn residues of CaM were obtained from PDB (PDB ID 2BBM). Initial structures were generated by the automated module, NOEASSIGN in CYANA. These NOE assignments were carefully confirmed and erroneous ones corrected through examination of spectra. Additional NOE were then added manually before recalculation of structures by CYANA. The final 100 structures were calculated, and the 20 conformers with the lowest target function values selected and further refined by the restrained simulated annealing and energy minimization algorithms in CNS 1.2 [73,74]. Graphical visualization and analyses of the structures were carried out with the programs MOLMOL [75] and PyMOL (DeLano Scientific, Palo Alto, CA, USA). The geometric and stereo-chemical quality of the ensemble of structures was validated by PROCHECK-NMR [76].

\subsection{Data Deposition}

${ }^{1} \mathrm{H},{ }^{13} \mathrm{C}$, and ${ }^{15} \mathrm{~N}$ chemical shift assignments were deposited in the Biological Magnetic Resonance Data Bank (http:/ / www.bmrb.wisc.edu) under accession code 15624. The coordinates of the final ensemble of 20 structures and the NMR restraints used for structural determination were deposited in the PDB under accession code 2JZI.

\subsection{Chemical Shift Deviation of CaM upon Association with CaNp}

Chemical shift perturbation map was used to identify the regions of CaM binding site. A single quantity used as normalized chemical shift perturbation of each residue $\left(\Delta \delta_{\text {residue }}\right)$ was expressed as:

$$
\Delta \delta_{\text {residue }}=\left\{\frac{1}{2}\left[\left(\Delta \delta_{H N}\right)^{2}+\left(\frac{\Delta \delta_{N}}{5}\right)^{2}\right]\right\}^{\frac{1}{2}}
$$

$\Delta \delta_{H N}$, and $\Delta \delta_{N}$ represent the chemical shift difference of CaM upon association with CaNp for amide proton and amide nitrogen nucleus, respectively. 


\subsection{Analysis of the Size and Molecular Weight of CaM/CaNp Complex by Dynamic Light Scattering (DLS)}

DLS measurements were carried out on a Zetasizer Nano-ZS instrument (Malvern instruments, Malvern, UK) equipped with a He/Ne laser running at $633 \mathrm{~nm}(4.0 \mathrm{~mW})$ as the light source. Time dependent fluctuations in the scattered light was detected by an avalanche photodiode and then passed to a digital correlator with a sampling time range from $0.5 \mu$ s to $80 \mathrm{~s}$. The autocorrelation function of the scattered light intensity data was then used to obtain the translational diffusion coefficient (D). The hydrodynamic radius $\left(\mathrm{R}_{\mathrm{H}}\right)$ and the size distribution of the molecules were derived from the Stokes-Einstein equation using the manufacturer's Nano software. Double logarithmic calibration curve of $R_{H}$ versus molecular weight $\left(M_{r}\right)$ of standard globular proteins was obtained, and used to estimate the molecular weight of the molecules. Standard protein samples used to obtain the calibration curve included bovine serum albumin $\left(\mathrm{M}_{\mathrm{r}} 67 \mathrm{kDa}\right), \mathrm{CaM}\left(\mathrm{M}_{\mathrm{r}} 16.7 \mathrm{kDa}\right)$, lysozyme $\left(\mathrm{M}_{\mathrm{r}} 14.7 \mathrm{kDa}\right)$, and ubiquitin $\left(\mathrm{M}_{\mathrm{r}} 8.4 \mathrm{kDa}\right)$. Samples $(1 \mathrm{mg} / \mathrm{mL}$ protein in $5 \mathrm{mM} \mathrm{CaCl} 2$ and $25 \mathrm{mM}$ Tris, $\mathrm{pH}$ 8.0) were filtered through pre-rinsed filter and a minimum 5 measurements per sample were made. The molecular weight of $\mathrm{CaM} / \mathrm{CaNp}$ complex was estimated by linear interpolation of the calibration curve.

\subsection{Secondary Structure Changes of CaM by Circular Dichroism Spectroscopy}

CD spectra were recorded on a 715 CD spectrometer (Jasco, Tokyo, Japan). CD spectra were collected using a cylindrical quartz cuvette with a $1 \mathrm{~mm}$ path-length. The step resolution was $0.2 \mathrm{~nm}$ with $1.0 \mathrm{~nm}$ bandwidth at a scan speed of $50 \mathrm{~nm} / \mathrm{min}$. Each CD spectrum was averaged over 16 measurements and corrected for the appropriate buffer baseline. The titration experiment was performed in which various amounts of CaNp were added to a fixed amount CaM. All spectra are presented as the molar CD absorption coefficient $\left(\Delta \varepsilon_{M}\right)$ using the molar concentration of CaM to facilitate direct comparison of free CaM and CaM/peptide complex. The difference between the CD spectra in the presence and the absence of the peptide was used to estimate the secondary structure of the peptide upon complex formation. Sample concentrations of CaM were $20 \mu \mathrm{M}, \mathrm{CaNp}$ were ranged from 1 to $30 \mu \mathrm{M}$.

\section{Conclusions}

Unraveling the diverse activation mechanisms and target recognition of CaM-dependent processes has received extensive attention in the past. The rules underlying the recognition of CaM with manifold target sequences have been proposed extensively and revised many times in literature. In this paper, we present the spectroscopic studies on CaM with the target sequence of CaN. Our results demonstrated that a new binding family 1-18 was found with major anchor residues Ile ${ }^{396}$, and Leu ${ }^{413}$ to allocate the largest space between two domains of CaM. Both the hydrophobic and electrostatic distribution determines the relative binding orientation of CaM-binding domain peptides. The relative orientation of CaNp to CaM is similar to the CaMKK peptide in the 1-16 binding mode, in which the Nand C-terminal hydrophobic anchors of target peptide were engulfed in the hydrophobic pockets of the $\mathrm{N}$ - and C-domain of CaM, respectively. In order to accommodate the longest spacing in the sequence, CaNp folds up into a V-shape helix with a kink in the middle. Based on our findings, we suggest that the hydrophobic interactions between the $\mathrm{Ca}^{2+}$-saturated C-domain and C-terminal half of the target sequence may provide driving force for the initial recognition. Subsequently folding up the target sequence and readjusting in the helix I of the N-domain allow the two domains of CaM to grab the target sequence. The electrostatic repulsion between CaM/CaNp complex and AID may result in the displacement of AID from active site to full activation. Our findings serve as a structural model for the recognition of $\mathrm{CaM}$ by $\mathrm{CaN}$, and provide new insights in the mechanism of activation of CaN.

Supplementary Materials: Supplementary Materials are available online.

Acknowledgments: This work was supported by research grants from Ministry of Science and Technology, Taiwan, MOST-105-2113-M-259-005 and MOST-106-2113-M-259-009 (to C.L.C). 
Author Contributions: C.-L.C. conceived and designed the experiments; D.I. and S.-M.L. performed the experiments; D.I. and C.-L.C. analyzed the data; C.-L.C. wrote the paper.

Conflicts of Interest: The authors declare no conflict of interest.

\section{References}

1. Chin, D.; Means, A.R. Calmodulin: A prototypical calcium sensor. Trends Cell Biol. 2000, 10, $322-328$. [CrossRef]

2. Yap, K.L.; Kim, J.; Truong, K.; Sherman, M.; Yuan, T.; Ikura, M. Calmodulin target database. J. Struct. Funct. Genom. 2000, 1, 8-14. [CrossRef]

3. Hoeflich, K.P.; Ikura, M. Calmodulin in action: Diversity in target recognition and activation mechanisms. Cell 2002, 108, 739-742. [CrossRef]

4. Zheng, J.; Varnum, M.D.; Zagotta, W.N. Disruption of an intersubunit interaction underlies $\mathrm{Ca}^{2+}$-calmodulin modulation of cyclic nucleotide-gated channels. J. Neurosci. 2003, 23, 8167-8175. [PubMed]

5. Ishida, H.; Vogel, H.J. Protein-peptide interaction studies demonstrate the versatility of calmodulin target protein binding. Protein Pept. Lett. 2006, 13, 455-465. [CrossRef] [PubMed]

6. Ikura, M.; Ames, J.B. Genetic polymorphism and protein conformational plasticity in the calmodulin superfamily: Two ways to promote multifunctionality. Proc. Natl. Acad. Sci. USA 2006, 103, 1159-1164. [CrossRef] [PubMed]

7. Abdel-Hamid, H.; Chin, K.; Shahinas, D.; Moeder, W.; Yoshioka, K. Calmodulin binding to Arabidopsis cyclic nucleotide gated ion channels. Plant Signal. Behav. 2010, 5, 1147-1149. [CrossRef] [PubMed]

8. Babu, Y.S.; Bugg, C.E.; Cook, W.J. Structure of calmodulin refined at 2.2 A resolution. J. Mol. Biol. 1988, 204, 191-204. [CrossRef]

9. Wilson, M.A.; Brunger, A.T. The 1.0 A crystal structure of $\mathrm{Ca}(2+)$-bound calmodulin: An analysis of disorder and implications for functionally relevant plasticity. J. Mol. Biol. 2000, 301, 1237-1256. [CrossRef] [PubMed]

10. Zhang, M.; Tanaka, T.; Ikura, M. Calcium-induced conformational transition revealed by the solution structure of apo calmodulin. Nat. Struct. Biol. 1995, 2, 758-767. [CrossRef] [PubMed]

11. Sorensen, B.R.; Shea, M.A. Interactions between domains of apo calmodulin alter calcium binding and stability. Biochemistry 1998, 37, 4244-4253. [CrossRef] [PubMed]

12. Gifford, J.L.; Walsh, M.P.; Vogel, H.J. Structures and metal-ion-binding properties of the Ca ${ }^{2+}{ }_{-}$binding helix-loop-helix EF-hand motifs. Biochem. J. 2007, 405, 199-221. [CrossRef] [PubMed]

13. Ikura, M.; Clore, G.M.; Gronenborn, A.M.; Zhu, G.; Klee, C.B.; Bax, A. Solution structure of a calmodulin-target peptide complex by multidimensional NMR. Science 1992, 256, 632-638. [CrossRef] [PubMed]

14. Meador, W.E.; Means, A.R.; Quiocho, F.A. Target enzyme recognition by calmodulin: 2.4 A structure of a calmodulin-peptide complex. Science 1992, 257, 1251-1255. [CrossRef] [PubMed]

15. Meador, W.E.; Means, A.R.; Quiocho, F.A. Modulation of calmodulin plasticity in molecular recognition on the basis of x-ray structures. Science 1993, 262, 1718-1721. [CrossRef] [PubMed]

16. Wall, M.E.; Clarage, J.B.; Phillips, G.N. Motions of calmodulin characterized using both Bragg and diffuse X-ray scattering. Structure 1997, 5, 1599-1612. [CrossRef]

17. Osawa, M.; Tokumitsu, H.; Swindells, M.B.; Kurihara, H.; Orita, M.; Shibanuma, T.; Furuya, T.; Ikura, M. A novel target recognition revealed by calmodulin in complex with Ca2+-calmodulin-dependent kinase kinase. Nat. Struct. Biol. 1999, 6, 819-824. [PubMed]

18. Elshorst, B.; Hennig, M.; Forsterling, H.; Diener, A.; Maurer, M.; Schulte, P.; Schwalbe, H.; Griesinger, C.; Krebs, J.; Schmid, H.; et al. Nmr solution structure of a complex of calmodulin with a binding peptide of the ca2+ pump. Biochemistry 1999, 38, 12320-12332. [CrossRef] [PubMed]

19. Kurokawa, H.; Osawa, M.; Kurihara, H.; Katayama, N.; Tokumitsu, H.; Swindells, M.B.; Kainosho, M.; Ikura, M. Target-induced conformational adaptation of calmodulin revealed by the crystal structure of a complex with nematode $\mathrm{ca}^{2+} /$ calmodulin-dependent kinase kinase peptide. J. Mol. Biol. 2001, 312, 59-68. [CrossRef] [PubMed]

20. Schumacher, M.A.; Rivard, A.F.; Bachinger, H.P.; Adelman, J.P. Structure of the gating domain of a ca $^{2+}$-activated $\mathrm{k}^{+}$channel complexed with $\mathrm{ca}^{2+} /$ calmodulin. Nature 2001, 410, 1120-1124. [CrossRef] [PubMed] 
21. Clapperton, J.A.; Martin, S.R.; Smerdon, S.J.; Gamblin, S.J.; Bayley, P.M. Structure of the complex of calmodulin with the target sequence of calmodulin-dependent protein kinase i: Studies of the kinase activation mechanism. Biochemistry 2002, 41, 14669-14679. [CrossRef] [PubMed]

22. Drum, C.L.; Yan, S.Z.; Bard, J.; Shen, Y.Q.; Lu, D.; Soelaiman, S.; Grabarek, Z.; Bohm, A.; Tang, W.J. Structural basis for the activation of anthrax adenylyl cyclase exotoxin by calmodulin. Nature 2002, 415, 396-402. [CrossRef] [PubMed]

23. Aoyagi, M.; Arvai, A.S.; Tainer, J.A.; Getzoff, E.D. Structural basis for endothelial nitric oxide synthase binding to calmodulin. EMBO J. 2003, 22, 766-775. [CrossRef] [PubMed]

24. Yamauchi, E.; Nakatsu, T.; Matsubara, M.; Kato, H.; Taniguchi, H. Crystal structure of a marcks peptide containing the calmodulin-binding domain in complex with $\mathrm{ca}^{2+}$-calmodulin. Nat. Struct. Biol. 2003, 10, 226-231. [CrossRef] [PubMed]

25. Contessa, G.M.; Orsale, M.; Melino, S.; Torre, V.; Paci, M.; Desideri, A.; Cicero, D.O. Structure of calmodulin complexed with an olfactory cng channel fragment and role of the central linker: Residual dipolar couplings to evaluate calmodulin binding modes outside the kinase family. J. Biomol. NMR 2005, 31, 185-199. [CrossRef] [PubMed]

26. Menetrey, J.; Bahloul, A.; Wells, A.L.; Yengo, C.M.; Morris, C.A.; Sweeney, H.L.; Houdusse, A. The structure of the myosin vi motor reveals the mechanism of directionality reversal. Nature 2005, 435, 779-785. [CrossRef] [PubMed]

27. Maximciuc, A.A.; Putkey, J.A.; Shamoo, Y.; Mackenzie, K.R. Complex of calmodulin with a ryanodine receptor target reveals a novel, flexible binding mode. Structure 2006, 14, 1547-1556. [CrossRef] [PubMed]

28. Ataman, Z.A.; Gakhar, L.; Sorensen, B.R.; Hell, J.W.; Shea, M.A. The nmda receptor nr1 c1 region bound to calmodulin: Structural insights into functional differences between homologous domains. Structure 2007, 15, 1603-1617. [CrossRef] [PubMed]

29. Ishida, H.; Borman, M.A.; Ostrander, J.; Vogel, H.J.; MacDonald, J.A. Solution structure of the calponin homology (ch) domain from the smoothelin-like 1 protein: A unique apocalmodulin-binding mode and the possible role of the c-terminal type-2 ch-domain in smooth muscle relaxation. J. Biol. Chem. 2008, 283, 20569-20578. [CrossRef] [PubMed]

30. Ishida, H.; Rainaldi, M.; Vogel, H.J. Structural studies of soybean calmodulin isoform 4 bound to the calmodulin-binding domain of tobacco mitogen-activated protein kinase phosphatase-1 provide insights into a sequential target binding mode. J. Biol. Chem. 2009, 284, 28292-28305. [CrossRef] [PubMed]

31. Ishida, H.; Vogel, J. The solution structure of a plant calmodulin and the CaM-binding domain of the vacuolar calcium-ATPase BCA1 reveals a new binding and activation mechanism. J. Biol. Chem. 2010, 285, 38502-38510. [CrossRef] [PubMed]

32. Juranic, N.; Atanasova, E.; Filoteo, A.G.; Macura, S.; Prendergast, F.G.; Penniston, J.T.; Strehler, E.E. Calmodulin wraps around its binding domain in the plasma membrane $\mathrm{Ca}^{2+}$ pump anchored by a novel 18-1 motif. J. Biol. Chem. 2010, 285, 4015-4024. [CrossRef] [PubMed]

33. Chen, A.S.; Kim, Y.M.; Gayen, S.; Huang, Q.; Raida, M.; Kang, C. Nmr structural study of the intracellular loop 3 of the serotonin 5-ht(1a) receptor and its interaction with calmodulin. Biochim. Biophys. Acta 2011, 1808, 2224-2232. [CrossRef] [PubMed]

34. Isozumi, N.; Iida, Y.; Nakatomi, A.; Nemoto, N.; Yazawa, M.; Ohki, S. Conformation of the calmodulin-binding domain of metabotropic glutamate receptor subtype 7 and its interaction with calmodulin. J. Biochem. 2011, 149, 463-474. [CrossRef] [PubMed]

35. Feldkamp, M.D.; Yu, L.; Shea, M.A. Structural and energetic determinants of apo calmodulin binding to the IQ motif of the $\mathrm{Na}(\mathrm{V}) 1.2$ voltage-dependent sodium channel. Structure 2011, 19, 733-747. [PubMed]

36. Chagot, B.; Chazin, W.J. Solution NMR structure of Apo-calmodulin in complex with the IQ motif of human cardiac sodium channel NaV1.5. J. Mol. Biol. 2011, 406, 106-119. [CrossRef] [PubMed]

37. Gifford, J.L.; Ishida, H.; Vogel, H.J. Structural insights into calmodulin-regulated L-selectin ectodomain shedding. J. Biol. Chem. 2012, 287, 26513-26527. [CrossRef] [PubMed]

38. Irene, D.; Huang, J.W.; Chung, T.Y.; Li, F.Y.; Tzen, J.T.; Lin, T.H.; Chyan, C.L. Binding orientation and specificity of calmodulin to rat olfactory cyclic nucleotide-gated ion channel. J. Biomol. Struct. Dyn. 2013, 31, 414-425. [CrossRef] [PubMed] 
39. Liu, Z.; Vogel, H.J. Structural basis for the regulation of L-type voltage-gated calcium channels: Interactions between the N-terminal cytoplasmic domain and $\mathrm{Ca}^{2+}$-calmodulin. Front. Mol. Neurosci. 2012, 5, 38. [CrossRef] [PubMed]

40. Tidow, H.; Nissen, P. Structural diversity of calmodulin binding to its target sites. FEBS J. 2013, 280, 5551-5565. [CrossRef] [PubMed]

41. Dunlap, T.B.; Guo, H.F.; Cook, E.C.; Holbrook, E.; Rumi-Masante, J.; Lester, T.E.; Colbert, C.L.; Vander Kooi, C.W.; Creamer, T.P. Stoichiometry of the calcineurin regulatory domain-calmodulin complex. Biochemistry 2014, 53, 5779-5790. [CrossRef] [PubMed]

42. Kranz, J.K.; Lee, E.K.; Nairn, A.C.; Wand, A.J. A direct test of the reductionist approach to structural studies of calmodulin activity: Relevance of peptide models of target proteins. J. Biol. Chem. 2002, 277, 16351-16354. [CrossRef] [PubMed]

43. Rhoads, A.R.; Friedberg, F. Sequence motifs for calmodulin recognition. FASEB J. 1997, 11, 331-340. [PubMed]

44. Yap, K.L.; Yuan, T.; Mal, T.K.; Vogel, H.J.; Ikura, M. Structural basis for simultaneous binding of two carboxy-terminal peptides of plant glutamate decarboxylase to calmodulin. J. Mol. Biol. 2003, 328, $193-204$. [CrossRef]

45. Klee, C.B.; Crouch, T.H.; Krinks, M.H. Calcineurin: A calcium- and calmodulin-binding protein of the nervous system. Proc. Natl. Acad. Sci. USA 1979, 76, 6270-6273. [CrossRef] [PubMed]

46. Rusnak, F.; Mertz, P. Calcineurin: Form and function. Physiol. Rev. 2000, 80, 1483-1521. [PubMed]

47. Crabtree, G.R. Calcium, calcineurin, and the control of transcription. J. Biol. Chem. 2001, 276, $2313-2316$. [CrossRef] [PubMed]

48. Ferri, A.; Nencini, M.; Battistini, S.; Giannini, F.; Siciliano, G.; Casali, C.; Damiano, M.G.; Ceroni, M.; Chio, A.; Rotilio, G.; et al. Activity of protein phosphatase calcineurin is decreased in sporadic and familial amyotrophic lateral sclerosispatients. J. Neurochem. 2004, 90, 1237-1242. [CrossRef] [PubMed]

49. Li, H.; Rao, A.; Hogan, P.G. Interaction of calcineurin with substrates and targeting proteins. Trends Cell Biol. 2011, 21, 91-103. [CrossRef] [PubMed]

50. Shah, S.Z.; Hussain, T.; Zhao, D.; Yang, L. A central role for calcineurin in protein misfolding neurodegenerative diseases. Cell. Mol. Life Sci. 2017, 74, 1061-1074. [CrossRef] [PubMed]

51. Hubbard, M.J.; Klee, C.B. Functional domain structure of calcineurin A: Mapping by limited proteolysis. Biochemistry 1989, 28, 1868-1874. [CrossRef] [PubMed]

52. Hashimoto, Y.; Perrino, B.A.; Soderling, T.R. Identification of an autoinhibitory domain in calcineurin. J. Biol. Chem. 1990, 265, 1924-1927. [PubMed]

53. Klee, C.B.; Draetta, G.F.; Hubbard, M.J. Calcineurin. Adv. Enzymol. Relat. Areas Mol. Biol. 1988, 61, 149-200. [PubMed]

54. Perrino, B.A.; Ng, L.Y.; Soderling, T.R. Calcium regulation of calcineurin phosphatase activity by its B subunit and calmodulin. Role of the autoinhibitory domain. J. Biol. Chem. 1995, 270, 7012. [CrossRef] [PubMed]

55. Kissinger, C.R.; Parge, H.E.; Knighton, D.R.; Lewis, C.T.; Pelletier, L.A.; Tempczyk, A.; Kalish, V.J.; Tucker, K.D.; Showalter, R.E.; Moomaw, E.W.; et al. Crystal structures of human calcineurin and the human fkbp12-fk506-calcineurin complex. Nature 1995, 378, 641-644. [CrossRef] [PubMed]

56. Rumi-Masante, J.; Rusinga, F.I.; Lester, T.E.; Dunlap, T.B.; Williams, T.D.; Dunker, A.K.; Weis, D.D.; Creamer, T.P. Structural basis for activation of calcineurin by calmodulin. J. Mol. Biol. 2012, 415, 307-317. [CrossRef] [PubMed]

57. Dunlap, T.B.; Cook, E.C.; Rumi-Masante, J.; Arvin, H.G.; Lester, T.E.; Creamer, T.P. The distal helix in the regulatory domain of calcineurin is important for domain stability and enzyme function. Biochemistry 2013, 52, 8643-8651. [CrossRef] [PubMed]

58. Li, S.J.; Wang, J.; Ma, L.; Lu, C.; Wang, J.; Wu, J.W.; Wang, Z.X. Cooperative autoinhibition and multi-level activation mechanisms of calcineurin. Cell Res. 2016, 26, 336-349. [CrossRef] [PubMed]

59. Ye, Q.L.; Wang, H.L.; Zheng, J.M.; Wei, Q.; Jia, Z.C. The complex structure of calmodulin bound to a calcineurin peptide. Proteins-Struct. Funct. Bioinform. 2008, 73, 19-27. [CrossRef] [PubMed]

60. Majava, V.; Kursula, P. Domain swapping and different oligomeric States for the complex between calmodulin and the calmodulin-binding domain of calcineurin A. PLoS ONE 2009, 4, e5402. [CrossRef] [PubMed]

61. Lin, T.H.; Huang, J.W.; Huang, H.B.; Chen, Y.C.; Liu, C.Y.; Lo, C.J.; Tang, T.C.; Chyan, C.L. ${ }^{1}$ H, ${ }^{15}$ N, and ${ }^{13} \mathrm{C}$ resonance assignments of calmodulin complexed with the calmodulin-binding domain of calcineurin. J. Biomol. NMR 2004, 29, 531-532. [CrossRef] [PubMed] 
62. Ye, Q.L.; Feng, Y.D.; Yin, Y.X.; Faucher, F.; Currie, M.A.; Rahman, M.N.; Jin, J.; Li, S.Z.; Wei, Q.; Jia, Z.C. Structural basis of calcineurin activation by calmodulin. Cell Signal. 2013, 25, 2661-2667. [CrossRef] [PubMed]

63. O’Donnell, S.E.; Yu, L.; Fowler, C.A.; Shea, M.A. Recognition of beta-calcineurin by the domains of calmodulin: Thermodynamic and structural evidence for distinct roles. Proteins 2011, 79, 765-786. [CrossRef] [PubMed]

64. Whitmore, L.; Wallace, B.A. DICHROWEB, an online server for protein secondary structure analyses from circular dichroism spectroscopic data. Nucleic Acids Res. 2004, 32, W668-W673. [CrossRef] [PubMed]

65. Whitmore, L.; Wallace, B.A. Protein secondary structure analyses from circular dichroism spectroscopy: Methods and reference databases. Biopolymers 2008, 89, 392-400. [CrossRef] [PubMed]

66. Klee, C.B.; Ren, H.; Wang, X. Regulation of the calmodulin-stimulated protein phosphatase, calcineurin. J. Biol. Chem. 1998, 273, 13367-13370. [CrossRef] [PubMed]

67. Tallant, E.A.; Wallace, R.W.; Cheung, W.Y. Purification and radioimmunoassay of calmodulin-dependent protein phosphatase from bovine brain. Methods Enzymol. 1983, 102, 244-256. [PubMed]

68. Wishart, D.S.; Bigam, C.G.; Yao, J.; Abildgaard, F.; Dyson, H.J.; Oldfield, E.; Markley, J.L.; Sykes, B.D. ${ }^{1}$ H, ${ }^{13} \mathrm{C}$ and ${ }^{15} \mathrm{~N}$ chemical shift referencing in biomolecular nmr. J. Biomol. NMR 1995, 6, 135-140. [CrossRef] [PubMed]

69. Herrmann, T.; Guntert, P.; Wuthrich, K. Protein NMR structure determination with automated NOE assignment using the new software CANDID and the torsion angle dynamics algorithm DYANA. J. Mol. Biol. 2002, 319, 209-227. [CrossRef]

70. Cornilescu, G.; Delaglio, F.; Bax, A. Protein backbone angle restraints from searching a database for chemical shift and sequence homology. J. Biomol. NMR 1999, 13, 289-302. [CrossRef] [PubMed]

71. Shen, Y.; Delaglio, F.; Cornilescu, G.; Bax, A. Talos+: A hybrid method for predicting protein backbone torsion angles from $\mathrm{nmr}$ chemical shifts. J. Biomol. NMR 2009, 44, 213-223. [CrossRef] [PubMed]

72. Wishart, D.S.; Sykes, B.D. The ${ }^{13} \mathrm{C}$ chemical-shift index: A simple method for the identification of protein secondary structure using ${ }^{13} \mathrm{C}$ chemical-shift data. J. Biomol. NMR 1994, 4, 171-180. [CrossRef] [PubMed]

73. Brunger, A.T.; Adams, P.D.; Clore, G.M.; DeLano, W.L.; Gros, P.; Grosse-Kunstleve, R.W.; Jiang, J.S.; Kuszewski, J.; Nilges, M.; Pannu, N.S.; et al. Crystallography \& nmr system: A new software suite for macromolecular structure determination. Acta Crystallogr. D 1998, 54, 905-921. [PubMed]

74. Schwieters, C.D.; Kuszewski, J.J.; Tjandra, N.; Clore, G.M. The xplor-nih nmr molecular structure determination package. J. Magn. Reson. 2003, 160, 65-73. [CrossRef]

75. Koradi, R.; Billeter, M.; Wuthrich, K. Molmol: A program for display and analysis of macromolecular structures. J. Mol. Graph. 1996, 14, 51-55. [CrossRef]

76. Laskowski, R.A.; Rullmannn, J.A.; MacArthur, M.W.; Kaptein, R.; Thornton, J.M. Aqua and procheck-nmr: Programs for checking the quality of protein structures solved by nmr. J. Biomol. NMR 1996, 8, 477-486. [CrossRef] [PubMed]

Sample Availability: The DNA plasmid corresponding to CaM is available from the authors.

(C) 2017 by the authors. Licensee MDPI, Basel, Switzerland. This article is an open access article distributed under the terms and conditions of the Creative Commons Attribution (CC BY) license (http:/ / creativecommons.org/licenses/by/4.0/). 